HENRIQUE SANTOS COSTA DE SOUZA

\title{
A Empresa e as Atividades na Área no Contexto do Direito do Mar e sua Normatização no Direito Brasileiro
}

\author{
Dissertação de Mestrado
}

Orientador: Professor Associado Dr. Wagner Menezes

UNIVERSIDADE DE SÃO PAULO

FACULDADE DE DIREITO

São Paulo - SP 
HENRIQUE SANTOS COSTA DE SOUZA

\section{A Empresa e as Atividades na Área no Contexto do Direito do Mar e sua Normatização no Direito Brasileiro}

Dissertação apresentada à Banca Examinadora do Programa de Pós-Graduação em Direito, da Faculdade de Direito, da Universidade de São Paulo, na área de concentração de Direito Internacional e Comparado, exigência parcial para obtenção do título de Mestre em Direito, sob a orientação do Professor Associado Dr. Wagner Menezes.

UNIVERSIDADE DE SÃO PAULO

FACULDADE DE DIREITO

São Paulo-SP 
Autorizo a reprodução e divulgação total ou parcial deste trabalho, por qualquer meio convencional ou eletrônico, para fins de estudo e pesquisa, desde que citada a fonte.

Serviço de Biblioteca e Documentação

Faculdade de Direito da Universidade de São Paulo

\footnotetext{
Costa de Souza, Henrique Santos

C872e A empresa e as atividades na Área no contexto do direito do mar e sua normalização no direito brasileiro / Henrique Santos Costa de Souza. -- São Paulo: USP / Faculdade de Direito, 2017.

$234 \mathrm{f}$.

Orientador: Prof. Wagner Menezes

Dissertação (Mestrado), Universidade de São Paulo, USP, Programa de Pós-Graduação em Direito, Direito Internacional e Comparado, 2017.

1. Direito internacional. 2. Direito do mar. 3. Empresa. 4. Atividades na Área. 5. Autoridade dos fundos marinhos internacionais. 6. Patrimônio comum da humanidade I. Menezes, Wagner. II. Título.
} 
A Banca Examinadora, abaixo assinada, aprova a Dissertação

\title{
A Empresa e as Atividades na Área no Contexto do Direito do Mar e sua Normatização no Direito Brasileiro
}

\author{
elaborada por
}

HENRIQUE SANTOS COSTA DE SOUZA

como requisito parcial para a obtenção do grau de

\section{MESTRE EM DIREITO INTERNACIONAL E COMPARADO}

\author{
BANCA EXAMINADORA:
}


Ao meu filho, Eduardo. 


\section{AGRADECIMENTOS}

Agradeço, inicialmente, à minha família, em especial aos meus pais, Vera Lúcia e Osvaldo, eternas inspirações, cujos laços transcendem a presente jornada, pessoas cujos exemplos e ensinamentos busco honrar em todos os atos da minha vida. À Carolina, minha esposa, pelo apoio e companheirismo em todos os momentos, os quais foram vitais para que eu pudesse persistir na construção deste estudo. Agradeço, ainda, ao Eduardo, ao Bernardo e ao Antônio, por constantemente me ensinarem a valorizar cada momento vivido.

Ao Professor Emérito da Faculdade de Direito do Largo São Francisco, Vicente Marotta Rangel, cujos inspiradores conselhos e diálogos, desde os tempos da minha graduação em Direito, especialmente quando da minha honrosa visita ao Tribunal Internacional do Direito do Mar, auxiliaram, sobremaneira, não somente na elaboração desta pesquisa, mas também no percurso acadêmico por mim percorrido. Nesta trajetória nas Arcadas, agradeço especialmente ao Professor Titular do Departamento de Direito Internacional e Comparado, Dr. Paulo Borba Casella, ao Professor Associado Dr. André de Carvalho Ramos e à Professora Dra. Elizabeth de Almeida Meirelles, cujos ensinamentos para sempre ficarão em minha memória. Ao Sr. Michael Lodge, Secretário Geral da Autoridade dos Fundos Marinhos Internacionais que, de forma tão amistosa, aconselhou-me quanto ao objeto pesquisado quando da minha visita ao mencionado organismo internacional, bem como à Sra. Michelle Bond, responsável pela biblioteca da Autoridade.

Agradeço, ainda, a todos os integrantes do Núcleo de Estudos em Tribunais Internacionais da Faculdade de Direito da Universidade de São Paulo (NETI-USP) e do Centro de Estudos em Direito do Mar da Universidade de São Paulo - "Vicente Marotta Rangel" (CEDMAR-USP-VMR), cujo compartilhamento de conhecimentos se mostra cada vez mais importante para a academia e para a sociedade. Sou grato às amizades iniciadas nas Arcadas, em especial: Ernesto Gomes, Paula Torres, Vitor Geromel, Carlos Campos, Eloá Figaro, José Daniel, Sibelle Walkiria, Natalia Sacchi, Jean Ditzz e Nathalia Duccini.

Finalmente, agradeço ao meu orientador, Professor Dr. Wagner Menezes, tanto por confiar em meu trabalho e oportunizar a indescritível experiência acadêmica desses últimos anos na Faculdade de Direito da Universidade de São Paulo, quanto por, ademais de nortear a presente pesquisa, servir de inspiração nos estudos e no desenvolvimento do Direito Internacional. 
COSTA DE SOUZA, Henrique Santos. A Empresa e as Atividades na Área no Contexto do Direito do Mar e sua Normatização no Direito Brasileiro. 234 páginas. Dissertação (Mestrado em Direito Internacional) - Departamento de Direito Internacional da Faculdade de Direito, Universidade de São Paulo-USP. São Paulo, 11 de Janeiro de 2017.

\section{RESUMO}

O tema desta pesquisa refere-se à possível atuação da Empresa como órgão operacional da Autoridade dos Fundos Marinhos Internacionais e às atividades realizadas na Área, no contexto do Direito do Mar, bem como sua normatização no Direito brasileiro. O estudo buscará comprovar a importância do desenvolvimento do Direito do Mar na evolução do Direito Internacional, resultando, especialmente, na Convenção de Montego Bay, a qual fundamenta a concretização de uma região marítima denominada "Área", reconhecida pela comunidade internacional como patrimônio comum da humanidade. Serão analisados os impactos jurídicos da eventual instalação da Empresa no território brasileiro, bem como serão averiguadas as responsabilidades e obrigações dos Estados patrocinadores em relação às atividades realizadas na Área, destacando-se o posicionamento da Câmara de Controvérsias dos Fundos Marinhos do Tribunal Internacional do Direito do Mar sobre o tema em questão. Será verificada a atuação da Companhia de Pesquisa de Recursos Minerais S/A, empresa patrocinada pelo Brasil na realização das atividades na Área junto à Elevação de Rio Grande, localizada sob o Oceano Atlântico, nos fundos marinhos internacionais, buscando-se aferir as repercussões na relação do Direito Internacional com o Direito brasileiro, bem como a promoção da paz a partir da primazia do Direito em um processo evolutivo de amadurecimento da comunidade internacional.

Palavras-chave: Direito Internacional. Direito do Mar. Empresa. Atividades na Área. Autoridade dos Fundos Marinhos Internacionais. Patrimônio comum da humanidade. 
COSTA DE SOUZA, Henrique Santos. The Enterprise and the Activities in the Area in the context of the Law of the Sea and its Regulation by the Brazilian Law. 234 pages. Master Degree - Faculty of Law, University of Sao Paulo, Sao Paulo, January, 11 ${ }^{\text {th }}, 2017$.

\begin{abstract}
The research theme refers to the possible function of the Enterprise as an operational organ of the International Seabed Authority and to the activities carried out in the Area, in the context of the Law of the Sea, as well as its regulation by the Brazilian Law. The study aims to prove the importance of the development of the Law of the Sea in the evolution of International Law, resulting, in particular, in the 1982 UN Convention for the Law of the Sea, which underlies the implementation of a maritime region called "Area", recognized by the international community as the common heritage of mankind. The legal impacts of the possible establishment of the Enterprise in Brazilian territory will be analyzed, as well as the responsibilities and obligations of the sponsoring States in relation to the activities carried out in the Area, highlighting the position of the Seabed Disputes Chamber of the International Tribunal for the Law of the Sea on the subject matter. The research will verify the performance of the Companhia de Pesquisa de Recursos Minerais S/A, a company sponsored by Brazil in order to carry out the activities in the Area specifically at the Rio Grande Rise, located in the international seabed under the Atlantic Ocean, in order to verify the repercussions in the relationship of International with Brazilian Law, as well as the promotion of peace through the rule of law in a evolutionary process of improvement of the international community.
\end{abstract}

Key words: International Law. Law of the Sea. Enterprise. Activities in the Area. International Seabed Authority. Common Heritage of Mankind. 


\section{LISTA DE CASOS}

"S.S. Wimbledon" (A01). Reino Unido da Grã-Bretanha e Irlanda do Norte v.

Alemanha. Corte Permanente de Justiça Internacional. 17 ago. 1923.

“Lotus” (A10). França v. Turquia. Corte Permanente de Justiça Internacional.

7 set. 1927.

"Canal de Corfu". Reino Unido da Grã-Bretanha e Irlanda do Norte v. Albânia.

Corte Internacional de Justiça. 9 abr. 1949.

"Responsabilidades e Obrigações dos Estados Patrocinadores de Pessoas e Entidades quanto às Atividades na Área (Pedido de Opinião Consultiva submetido à Câmara de Controvérsias dos Fundos Marinhos)". Tribunal Internacional do Direito do Mar. 1 fev. 2011

$62,69,89$,

143,164

166 , Sub.

2.7 (Passim)

"Pesca Anglo-Norueguesa". Reino Unido da Grã-Bretanha e Irlanda do Norte v.

Noruega. Corte Internacional de Justiça. 18 dez. 1951.

"Pesca de Baleias na Antártica". Austrália v. Japão e Nova Zelândia. Corte Internacional de Justiça. 31 mar. 2014.

"Reparação de Danos Sofridos por Agentes a Serviço da Organização das Nações Unidas". Corte Internacional de Justiça. 11 abr. 1949.

“ARA Libertad". Argentina v. Gana. Medida Provisória. Tribunal Internacional do Direito do Mar. 15 dez. 2012.

"Arctic Sunrise". Reino dos Países Baixos v. Federação Russa. Medida Provisória. Tribunal Internacional do Direito do Mar. 22 nov. 2013..

"Consequências Jurídicas aos Estados quanto à Presença Contínua da África do Sul na Namíbia apesar da Resolução n. 276 (1970) do Conselho de Segurança da Organização das Nações Unidas". Parecer Consultivo. Corte Internacional de Justiça. 21 jun. 1971.

"Caso Relativo à Conservação e Explotação Sustentável do Peixe Espada no Sudeste do Oceano Pacífico". Chile/União Europeia. Tribunal Internacional do Direito do Mar. 16 dez. 2009...

"M/V SAIGA". São Vicente e Granadinas v. Guiné. Tribunal Internacional do Direito do Mar. 1 jul. 1999.

“M/V VIRGINIA G”. Panamá/Guiné-Bissau. Tribunal Internacional do Direito do Mar. 14 abr. 2014.

"Fábrica de Chorzów”. Corte Permanente de Justiça Internacional. 26 jul. 1927....

"Fábrica de Celulose no Rio Uruguai". Argentina v. Uruguai. Corte Internacional de Justiça. 20 abr. 2010.

"Conformidade da Declaração Unilateral de Independência de Kosovo com o Direito Internacional”. Opinião Consultiva. Corte Intern. de Justiça. 22 jul. 2010.

"Saara Ocidental”. Opinião Consultiva. Corte Internacional de Justiça. 15 out. 1975.

"Pedido de Opinião Consultiva Submetido pela Comissão Sub-Regional de Pesca (SRFC)". Opinião Consultiva. Trib. Internacional do Direito do Mar. 2 abr. 2015. 
"Recurso Extraordinário 460.320 (PR)". Supremo Tribunal Federal. Plenário.

Rel. Min. Gilmar Mendes. 31 ago. 2011

“Recurso Extraordinário 80.004". Supremo Tribunal Federal. Tribunal Pleno.

Rel. Min. Xavier de Albuquerque. 1 jun. 1977.

“Apelação Cível 9.587-DF”. Supremo Tribunal Federal. Segunda Turma. Rel. Min. Lafayette de Andrada. 21 ago. 1951.... 


\section{LISTA DE TERMOS E SIGLAS}

Autoridade

CIJ

CIRM

CLCS

CLPC

CNUDM

CPJI

CPRM

EUA

GATT

ITLOS

ISA

LEPLAC

ONU

PNRM

PNUD

PROAREA

STF

UNCLOS
Autoridade dos Fundos Marinhos Internacionais

Corte Internacional de Justiça

Comissão Interministerial para os Recursos do Mar

Commission on the Limits of the Continental Shelf

Comissão dos Limites da Plataforma Continental

Convenção das Nações Unidas do Direito do Mar de 1982

Corte Permanente de Justiça Internacional

Companhia de Pesquisa de Recursos Minerais

Estados Unidos da América

Acordo Geral sobre Tarifas e Comércio

Tribunal Internacional do Direito do Mar

International Seabed Authority

Plano de Levantamento da Plataforma Continental Brasileira

Organização das Nações Unidas

Política Nacional para os Recursos do Mar

Programa das Nações Unidas para o Desenvolvimento

Programa de Prospecção e Exploração de Recursos Minerais da Área

Internacional do Atlântico Sul e Equatorial

Supremo Tribunal Federal

Convenção das Nações Unidas do Direito do Mar de 1982 


\section{SUMÁRIO}

INTRODUÇÃO. 12

1 O DIREITO DO MAR, O ALTO MAR E OS FUNDOS MARINHOS INTERNACIONAIS.

1.1 A EVOLUÇÃO HISTÓRICA DO DIREITO DO MAR.

1.2 A IMPORTÂNCIA DO DIREITO DO MAR NA EVOLUÇÃO DO DIREITO INTERNACIONAL

1.3 OS TRATADOS SOBRE O DIREITO DO MAR E A CONVENÇÃO DAS

NAÇÕES UNIDAS SOBRE O DIREITO DO MAR DE 1982 ............................................36

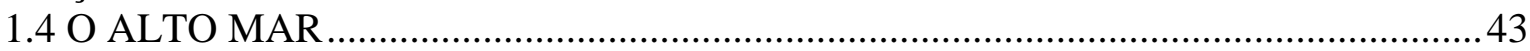

1.5 OS FUNDOS MARINHOS INTERNACIONAIS ……………………………….....4

1.6 PRINCÍPIOS E REGIME JURÍDICO QUE REGEM O ALTO MAR ……………........51

1.7 PRINCÍPIOS E REGIME JURÍDICO QUE REGEM OS FUNDOS MARINHOS

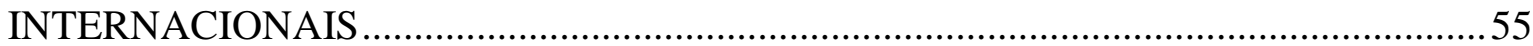

1.8 O PRINCÍPIO DO PATRIMÔNIO COMUM DA HUMANIDADE APLICADO

À ÁREA.

1.9 O ALTO MAR E OS FUNDOS MARINHOS INTERNACIONAIS NA

CONTEMPORANEIDADE DO DIREITO INTERNACIONAL ..........................................69

2 A AUTORIDADE DOS FUNDOS MARINHOS INTERNACIONAIS E A

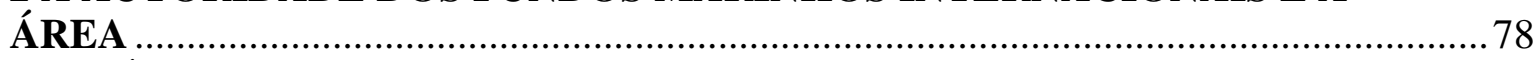

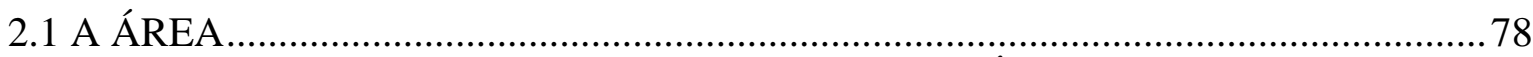

2.1.1 Os nódulos polimetálicos e as demais riquezas da Área ......................................... 86

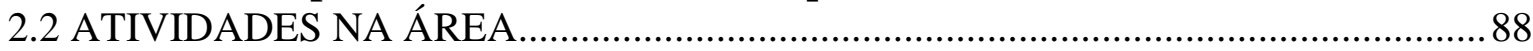

2.3 AS ENTIDADES E AS ATIVIDADES NA ÁREA ……………………………......93

2.4 A AUTORIDADE DOS FUNDOS MARINHOS INTERNACIONAIS ......................96

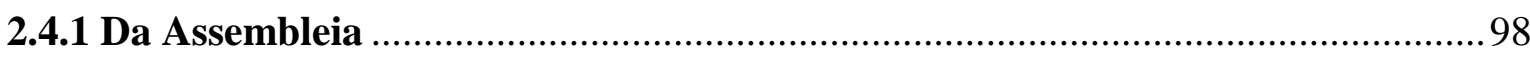

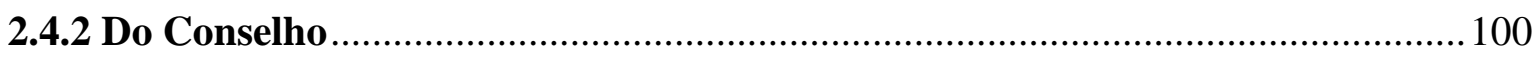

2.4.2.1 Da Comissão Jurídica e Técnica ........................................................................103

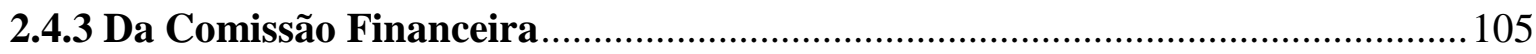

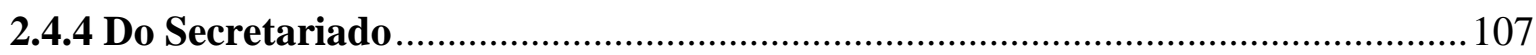

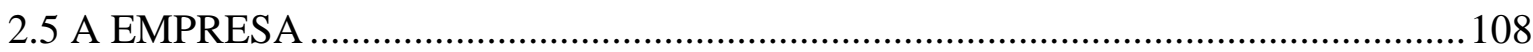

2.6 O TRIBUNAL INTERNACIONAL DO DIREITO DO MAR E A CÂMARA

DE CONTROVÉRSIAS DOS FUNDOS MARINHOS ..................................................... 114

2.7 A RESPONSABILIDADE DOS ESTADOS PATROCINADORES E A OPINIÃO CONSULTIVA DA CÂMARA DE CONTROVÉRSIAS DOS FUNDOS MARINHOS

2.8 OS ESTADOS EM DESENVOLVIMENTO E AS ATIVIDADES

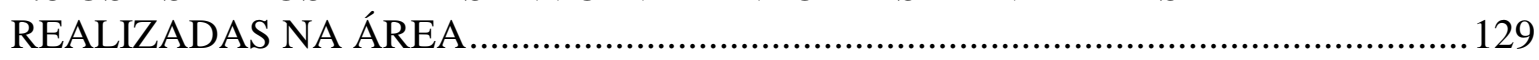

2.9 A NORMATIZAÇÃO DERIVADA PARA OS FUNDOS MARINHOS

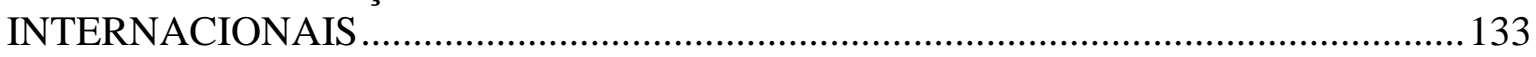

3 A EMPRESA, AS ATIVIDADES NA ÁREA E O DIREITO BRASILEIRO ........137

3.1 AS REGIÕES MARÍTIMAS CONCEDIDAS PARA ATIVIDADES NA

ÁREA. 
3.2 OS CONTRATANTES AUTORIZADOS PELA AUTORIDADE DOS FUNDOS MARINHOS INTERNACIONAIS PARA EXERCEREM

ATIVIDADES NA ÁREA.

3.3 A COMPANHIA DE PESQUISA DE RECURSOS MINERAIS E AS

ATIVIDADES NA ELEVAÇÃO DO RIO GRANDE

3.4 OS ESTADOS PATROCINADORES NO QUADRO INTERNACIONAL

E SUA NORMATIZAÇÃO INTERNA DAS ATIVIDADES REALIZADAS

NA ÁREA

3.5 O BRASIL COMO ESTADO PATROCINADOR E SUA NORMATIZAÇÃO

INTERNA DAS ATIVIDADES REALIZADAS NA ÁREA

3.6 O BRASIL COMO ESTADO PATROCINADOR E O PODER JUDICIÁRIO

BRASILEIRO

3.7 A EMPRESA E O DIREITO BRASILEIRO

3.8 O PRINCÍPIO DO PATRIMÔNIO COMUM DA HUMANIDADE, O

BRASIL E AS ATIVIDADES NA ÁREA REALIZADAS POR

ENTIDADES BRASILEIRAS

3.9 ANÁLISE E PERSPECTIVAS DA EMPRESA NA CONTEMPORANEIDADE

DO DIREITO INTERNACIONAL

CONCLUSÃO

BIBLIOGRAFIA 


\section{INTRODUÇÃO}

A constante evolução do Direito Internacional e o coexistente aperfeiçoamento tecnológico, relativos ao Direito do Mar, fundamentam o desenvolvimento das mais diversas atividades realizadas nos oceanos e nos fundos marinhos. A institucionalização, sistematização e jurisdicionalização do Direito Internacional, desenvolvidas com o avanço do respectivo sistema jurídico, sedimentam uma rota que consolida a promoção da paz em um contexto de permanente progresso civilizatório da comunidade internacional.

Com o desenvolvimento do Direito Internacional, do conhecimento, da tecnologia e das ciências em geral, restaram comprovados avanços relacionados à exploração de uma região marítima que, no teor da Convenção de Montego Bay, viria a ser reconhecida como "patrimônio comum da humanidade", cujo aproveitamento deve beneficiar a todos os povos. Trata-se dos fundos marinhos internacionais que, juntamente com o leito do mar e do seu subsolo, fazem parte do que a Convenção de Montego Bay chama de "Área". Em 1967, Arvid Pardo, representante de Malta junto à ONU, realizou um importante discurso na respectiva Assembleia Geral, abordando os avanços relacionados à exploração de minérios, petróleo e gás natural dessa região. Da mesma forma como o tamanho do mar sob jurisdição estatal impacta diretamente na extensão do alto mar, o mesmo ocorre com a relação existente entre a extensão da plataforma continental sob jurisdição dos Estados e os fundos marinhos internacionais. Diferente do princípio da liberdade que correntemente, de modo geral, rege o alto mar, consolidou-se o princípio do patrimônio comum da humanidade aplicado aos fundos marinhos que não se encontram sob jurisdição de nenhum Estado em específico, mas que estão submetidos a um sistema fundamentado, especialmente, na Convenção de Montego Bay. Sua institucionalização e sistema legal se respaldam, particularmente, em um tripé institucional: a Comissão dos Limites da Plataforma Continental, o Tribunal Internacional do Direito do Mar e a Autoridade dos Fundos Marinhos Internacionais, sendo esta última responsável por organizar e controlar as atividades na Área, especialmente no que se refere à administração dos recursos dessa região marítima.

Contemporaneamente, a Autoridade dos Fundos Marinhos Internacionais, além de servir de foro internacional de desenvolvimento de leis nacionais relacionadas às atividades realizadas na Área, firmou diversos contratos de exploração de minérios localizados nos fundos marinhos internacionais com vários países e empresas patrocinadas 
pelas nações com as quais tem vínculo efetivo de nacionalidade. Destaca-se que, em 2011, o próprio Tribunal Internacional do Direito do Mar publicou seu entendimento sobre a responsabilidade e as obrigações dos Estados patrocinadores quanto às atividades realizadas na Área.

Com o desenvolvimento de tecnologia que viabilize o aproveitamento economicamente viável dos recursos localizados na Área, a tendência é que haja um crescimento do interesse por atividades realizadas nessa região marítima, tanto pelos próprios países quanto por empresas, impulsionando o funcionamento de um sistema jurídico internacional embasado, especialmente, na Convenção da ONU sobre o Direito do Mar de 1982, bem como no referido tripé institucional. Além do viés internacional relacionado às atividades realizadas nos fundos marinhos sob jurisdição da Autoridade, há o caráter de análise das leis brasileiras sobre o tema, considerando-se a necessidade tanto da constante evolução legislativa sobre essas atividades quanto do permanente progresso interpretativo do Direito Internacional e de sua relação com o Direito Interno por parte do Poder Judiciário brasileiro, dos juristas, magistrados, legisladores, instituições e demais operadores do Direito.

Desta forma, o objetivo desta dissertação de mestrado é compreender tanto o sistema jurídico que regulamenta a função da Autoridade dos Fundos Marinhos Internacionais quanto a organização e controle das atividades de aproveitamento dos recursos minerais localizados nos fundos marinhos situados na Área. Almeja-se, também, pesquisar a atividade do Tribunal Internacional do Direito do Mar, das empresas exploradoras e dos respectivos Estados patrocinadores na realização das atividades na referida região marítima, tendo como parâmetro o reconhecimento desse espaço internacional marítimo como patrimônio comum da humanidade. Com enfoque na contemporaneidade do Direito Internacional, o estudo busca, ainda, esclarecer se a Autoridade tem cumprido a sua função de organizar e controlar as atividades relacionadas ao aproveitamento dos minerais da Área, atendendo às necessidades da sociedade internacional, com destaque à normatização dessas atividades no Direito brasileiro.

Ressalta-se que, embora o tema abordado no presente estudo tenha, em sua essência, um caráter multi e interdisciplinar, abrangendo diversas áreas da Ciência e do Conhecimento, como a Oceanografia, a Engenharia e as tecnologias especializadas, bem como variadas disciplinas, tais como a comercial, a política, a social, a das relações internacionais, a financeira, a econômica e a administrativa, a pesquisa busca contribuir particularmente no âmbito jurídico, fundamentando-se em uma análise do Direito 
Internacional e, mais especificamente, do Direito do Mar, bem como sua relação com o Direito Nacional. Não há, contudo, a pretensão de abordar, ou pormenorizar, as diversas disciplinas e áreas da Ciência e do Conhecimento aplicadas ao tema em questão. A eventual atuação da Empresa como órgão operacional da Autoridade dos Fundos Marinhos Internacionais, as atividades na Área no contexto do Direito do Mar e sua normatização no Direito brasileiro, portanto, constituem o tema a ser desenvolvido nesta dissertação de mestrado.

O estudo aborda, inicialmente, a evolução histórica do Direito do Mar, e a importância desse ramo do Direito na evolução do Direito Internacional. O estudo também faz referência aos Tratados sobre o Direito do Mar, com ênfase na Convenção das Nações Unidas sobre o Direito do Mar de 1982. Trata-se, pois, dos espaços internacionais marítimos, especialmente o alto mar e os fundos marinhos internacionais, debatendo-se os fundamentos jurídicos relativos à caracterização da região que a referida Convenção de 1982 denomina como "Área" como sendo patrimônio comum da humanidade. A partir disso, o estudo pretende analisar a atuação da Autoridade dos Fundos Marinhos Internacionais no que tange à organização e controle das atividades de aproveitamento dos minérios localizados nos fundos marinhos situados na região além da jurisdição dos Estados. Destaca-se a atuação do Tribunal Internacional do Direito do Mar, sobretudo, da sua Câmara de Controvérsias dos Fundos Marinhos. Para o levantamento dessas informações foram pesquisados os órgãos que fazem parte da Autoridade dos Fundos Marinhos Internacionais, ressaltando-se a contingente atuação da Empresa enquanto órgão por intermédio do qual a Autoridade deverá exercer as funções de exploração, aproveitamento, transporte, processamento e comercialização dos minerais extraídos da Área.

A pesquisa, destarte, busca esclarecer a atuação da Autoridade dos Fundos Marinhos Internacionais, almejando maior compreensão sobre o funcionamento do sistema jurídico que embasa a realização das atividades na região marítima sob sua jurisdição. A questão será analisada desde a evolução da conceituação jurídica de "liberdade do alto mar", desenvolvida no Direito Internacional clássico, levando à elucidação do reconhecimento da Área, pela comunidade internacional, como patrimônio comum da humanidade, em um estudo de grande importância para o Direito Internacional contemporâneo. Para o desenvolvimento desta dissertação de mestrado, os contornos da pesquisa serão delimitados em relação ao tema, considerando-se, especialmente, a atuação da Autoridade dos Fundos Marinhos Internacionais e do Tribunal Internacional do Direito 
do Mar no que se refere às atividades realizadas na Área. A avaliação dessas atividades, por sua vez, ocorrerá, também, segundo preceitos do Direito brasileiro, considerando-se, ademais, a realização dessas atividades por entidades patrocinadas pelo Brasil. Será analisada, ainda, a exploração da Elevação de Rio Grande, localizada nos fundos marinhos internacionais sob o Oceano Atlântico, pela Companhia de Pesquisa de Recursos Minerais, empresa vinculada ao Ministério de Minas e Energia. Ao buscar os fundamentos e a natureza jurídica da atuação da referida Autoridade dos Fundos Marinhos Internacionais, o estudo permitirá investigar as responsabilidades e as obrigações dos Estados patrocinadores em relação às atividades na Área, considerando não somente o posicionamento da Câmara de Controvérsias dos Fundos Marinhos do Tribunal Internacional do Direito do Mar como, também, o entendimento da própria Autoridade sobre o tema em questão. O estudo considerará, ainda, a análise da normatização da matéria no Brasil, tendo como parâmetro a Convenção das Nações Unidas sobre o Direito do Mar de 1982, o Acordo para Implementação da Parte XI da mencionada Convenção e as respectivas normas deles derivadas.

Esta pesquisa almeja averiguar a atuação da Autoridade dos Fundos Marinhos Internacionais na organização, no controle e na realização das atividades na Área, especialmente do seu órgão operacional e comercial, denominado Empresa, e busca responder, entre outras, as seguintes questões: Qual é a importância do Direito do Mar na evolução do Direito Internacional e quais os fundamentos relativos à caracterização dos fundos marinhos internacionais como patrimônio comum da humanidade, considerando-se as consequências desse reconhecimento pela comunidade internacional na contemporaneidade? Quais as características dos princípios jurídicos e das normas que regem o alto mar e os fundos marinhos internacionais, considerando a construção histórica de acordo com o estágio evolutivo do Direito Internacional? Como funciona a Autoridade dos Fundos Marinhos Internacionais na organização, realização e controle das atividades realizadas na Área, bem como na representação dos interesses da humanidade no Direito Internacional contemporâneo? Qual é a atual situação relativa à criação da Empresa como órgão operacional da Autoridade dos Fundos Marinhos Internacionais para realização das atividades na Área e suas consequências e implicações tanto perante o Direito Internacional quanto perante o Direito brasileiro? Quais são as normas, as instituições e os princípios que regem a realização das atividades na Área pela Companhia de Pesquisa de Recursos Minerais S/A, especificamente na Elevação do Rio Grande, num contexto em que o Brasil é seu Estado patrocinador, considerando-se a normatização dessas atividades no 
Direito Internacional e no Direito brasileiro? Quais são os desafios enfrentados na relação do Direito Internacional com o Direito brasileiro, no que se refere tanto às atividades realizadas na Área quanto à possível criação da Empresa e sua instalação em território brasileiro, em um contexto de unidade sistêmica na qual o Direito Internacional e o Direito brasileiro se inter-relacionam, considerando-se as normas, tratados, princípios e instituições existentes no âmbito internacional e nacional?

Para responder às questões anteriormente propostas dentro de um marco teórico idealista, fundamentado especialmente nas normas, nos tratados e nos princípios que regem o Direito Internacional, o presente estudo será dividido em três capítulos. O estudo consistirá de uma pesquisa exploratória e explicativa, utilizando-se o método analíticoinvestigativo, e partirá de um levantamento bibliográfico e revisional sobre as primeiras menções feitas sobre o tema em questão, com base em autores do Direto Internacional clássico e contemporâneo, inclusive com uma análise contemporânea do Direito Internacional e sobre as principais correntes jus-internacionalistas relativas à matéria estudada e os tratados, com o objetivo de delinear um panorama sobre a evolução do objeto de estudo. Além disso, será utilizado o método dedutivo-histórico, realizando-se um retrospecto embasado no Direito Internacional clássico, bem como em uma análise contemporânea que fundamenta o desenvolvimento da Convenção das Nações Unidas sobre o Direito do Mar de 1982 e a constituição de organizações internacionais que tratam do tema estudado, destacando-se a Autoridade dos Fundos Marinhos Internacionais, o Tribunal Internacional do Direito do Mar e a Comissão dos Limites da Plataforma Continental. A partir dessa pesquisa será possível realizar um estudo que permitirá chegar a conclusões utilizando-se o método dialético por meio da exposição e análise dos diferentes e divergentes pensamentos sobre os assuntos tratados no estudo apresentado. Como fontes de estudo serão utilizadas as obras originais de maior relevância sobre o tema, além de artigos científicos, tratados, jurisprudência, opiniões consultivas e julgados de tribunais internacionais e nacionais, bem como regramentos estabelecidos pela Autoridade dos Fundos Marinhos Internacionais, destacando-se uma entrevista realizada pessoalmente com o Sr. Michael Lodge, representante da Autoridade dos Fundos Marinhos Internacionais, eleito em julho de 2016 como Secretário Geral dessa organização internacional.

No primeiro capítulo será abordada a evolução histórica do Direito do Mar, investigando-se a sua importância e protagonismo no desenvolvimento do Direito Internacional, com fundamento nos jusinternacionalistas clássicos e contemporâneos. Será 
destacada a consolidação de uma institucionalização, sistematização e jurisdicionalização do Direito Internacional, bem como a evolução do Direito do Mar, sua estruturação jurídica e organizacional desde a criação do Estatuto da Corte Internacional de Presas Marítimas, em 1907, passando pelo julgamento de casos pela Corte Permanente de Justiça Internacional, pela Corte Internacional de Justiça e pelo Tribunal Internacional do Direito do Mar. Na sequência serão analisados os principais tratados sobre o Direito do Mar até a consolidação da Convenção das Nações Unidas sobre o Direito do Mar de 1982. Serão estudados, também, dois espaços marítimos internacionais, quais sejam, o alto mar e os fundos marinhos internacionais, com vistas a pesquisar a evolução de princípios e regimes jurídicos distintos que, atualmente, regem esses espaços. Finalmente, será analisado o princípio do patrimônio comum da humanidade, bem como o alto mar e os fundos marinhos internacionais na contemporaneidade do Direito Internacional.

No segundo capítulo será realizada uma análise específica da Área, com base na Convenção das Nações Unidas sobre o Direito do Mar de 1982, bem como na respectiva doutrina que fundamenta a evolução do Direito Internacional quanto às atividades de aproveitamento dos recursos localizados nos fundos marinhos internacionais. Por intermédio de um estudo analítico-descritivo será pesquisado o funcionamento da Autoridade dos Fundos Marinhos Internacionais, especificamente quanto à atuação da Assembleia, do Conselho, do Secretariado, da Comissão Jurídica e Técnica e da Comissão Financeira. Será estudado, ainda, o funcionamento da Empresa, prescrito na Convenção de Montego Bay, como órgão operacional da referida Autoridade responsável pela execução das atividades na Área, bem como pelo transporte, processamento e comercialização dos recursos encontrados na referida região dos fundos marinhos internacionais. Abordar-se-á, ainda, a atuação do Tribunal Internacional do Direito do Mar, em especial a respectiva Câmara de Controvérsias dos Fundos Marinhos, bem como serão analisados os assuntos relacionados à responsabilidade dos Estados patrocinadores e à transferência de tecnologia aos Estados em desenvolvimento.

No terceiro e último capítulo será desenvolvido o objetivo principal da pesquisa, iniciando pela análise das regiões marítimas internacionais concedidas pela Autoridade dos Fundos Marinhos Internacionais para a realização das atividades na Área, bem como das entidades autorizadas para a realização dessas atividades. Será destacada, entre elas, a Companhia de Pesquisa de Recursos Minerais e suas atividades na Elevação do Rio Grande, tendo o Brasil como Estado patrocinador. Será abordada, também, a normatização interna dos países sobre as atividades realizadas na Área, evidenciando o Brasil como 
Estado patrocinador, bem como a inter-relação do Direito Internacional com o Direito brasileiro. Além do viés normativo, estudar-se-á o atual entendimento do Supremo Tribunal Federal sobre a relação do Direito Internacional e o Direito Interno do país, demonstrando o complexo ambiente jurídico no qual se encontram, especificamente, as atividades a serem realizadas nos fundos marinhos internacionais, seja por entidades patrocinadas pelo Brasil, seja mediante a atuação da Empresa após sua eventual criação e sua instalação em território brasileiro. Será destacado o princípio do patrimônio comum da humanidade e sua relação com o Brasil e a entidade por ele patrocinada, pretendendo-se analisar as perspectivas da atuação da Empresa na contemporaneidade do Direito Internacional, bem como se a atuação da Autoridade dos Fundos Marinhos Internacionais reflete os interesses da comunidade internacional.

O tema central do presente estudo buscará fundamentar-se na análise da eventual atuação da Empresa como órgão operacional da Autoridade dos Fundos Marinhos Internacionais no que se refere às atividades realizadas na Área. Além de considerar o viés do Direito Internacional, o estudo tratará, também, da normatização dessas atividades pelo Direito brasileiro em um contexto no qual o país se insere como Estado patrocinador, ambientando-se na constante evolução do Direito, da sociedade internacional, das normas e dos princípios que regem o mencionado espaço marítimo considerado patrimônio comum da humanidade. 


\section{CONCLUSÃO}

A evolução do Direito do Mar, além de acompanhar o progresso histórico do Direito Internacional, mostra-se importante em diversas oportunidades e, muitas vezes, evidencia o seu caráter vanguardista, especialmente no que se refere à institucionalização, sistematização e jurisdicionalização do Direito Internacional. Enquanto prevaleceu no Direito Internacional clássico a discussão sobre a extensão da jurisdição estatal na dimensão horizontal do espaço marítimo, consolidando-se o princípio da liberdade aplicado ao alto mar, o Direito Internacional contemporâneo tratou da mesma questão quanto à amplitude da jurisdição dos Estados na dimensão vertical do espaço marítimo, assentando o princípio do patrimônio comum da humanidade aplicado à Área.

A criação do tripé institucional, embasado na Convenção de Montego Bay, fundamenta o funcionamento do Direito do Mar na contemporaneidade e consolida a evolução organizacional que remete a um contexto do início do século XX, quando houve a criação do estatuto da Corte Internacional de Presas Marítimas, conjuntura na qual o Brasil, especialmente por intermédio de Rui Barbosa, se posicionou em relação ao desenvolvimento do princípio da igualdade entre os Estados. Recorda-se que a importância desta Corte encontrava-se não somente no estabelecimento de um sistema judicial internacional, como na institucionalização de um órgão que refletia um embrião institucional de superação do paradigma exclusivamente interestatal de acesso à justiça internacional, garantindo essa possibilidade, também, a indivíduos e empresas, em um âmbito universal.

O progresso do Direito Internacional culminou com a evolução tanto das normas que regem os mares, mormente fundamentadas pela Convenção de Montego Bay e por sua normatização derivada, quanto das instituições que embasam essa constante evolução, atualmente representadas, especialmente, pela Comissão dos Limites da Plataforma Continental, pelo Tribunal Internacional do Direito do Mar e pela Autoridade dos Fundos Marinhos Internacionais.

A criação da Autoridade dos Fundos Marinhos Internacionais consolidou o desenvolvimento do conceito da humanidade como destinatária e beneficiária das normas internacionais de vocação universal, sendo que o status nascendi relacionado à sua capacidade de agir junto a Tribunais Internacionais encontra na Autoridade uma forma de representação de seus interesses, legitimada pela Convenção da ONU sobre o Direito do 
Mar de 1982. Da mesma forma como a Autoridade dos Fundos Marinhos Internacionais representa a humanidade e seus interesses no contexto do Direito Internacional contemporâneo, a Empresa - como entidade híbrida de caráter dual e órgão operacional e comercial da Autoridade - traduz a representação da humanidade na intervenção direta no domínio econômico ao lado de agentes estatais e privados, devendo equilibrar sua operação de acordo com sólidos princípios comerciais para a realização de metas lucrativas, sem prejudicar o interesse público oriundo da aplicação do princípio do patrimônio comum da humanidade à Área.

Caso o presente processo de efetivação da Empresa - primeira organização internacional comercial - como órgão operacional da Autoridade, o qual atualmente se encontra paralisado, venha a ser efetivado, comprovará o constante progresso do Direito Internacional e da evolução de suas instituições pela comunidade internacional. Essa evolução se refere à representação dos interesses da humanidade no contexto comercial e econômico, com o fortalecimento dos consagrados elementos que já fundamentam o princípio do patrimônio comum da humanidade aplicado à Área, quais sejam: a proibição de proclamação de soberania dos Estados, sua utilização para fins pacíficos, o compartilhamento da gestão dos recursos, a partilha dos benefícios decorrentes de sua exploração em benefício da humanidade, o interesse da humanidade com destaque ao interesse dos Estados em desenvolvimento e a proteção e preservação do meio ambiente marinho.

Sendo assim, resta nítida a consolidação do princípio do patrimônio comum da humanidade na contemporaneidade do Direito Internacional, com seu caráter harmonizante, transespacial, intertemporal, universalista e igualitário, em benefício da coletividade humana e das gerações atuais e futuras de todos os povos. Acrescente-se a isso a atuação da Autoridade dos Fundos Marinhos Internacionais como organização internacional efetivamente responsável, por intermédio dos órgãos que dela fazem parte, pela organização, realização e controle das atividades realizadas na Área, especialmente com vistas à gestão dos respectivos recursos minerais, bem como a possibilidade de utilização do Tribunal Internacional do Direito do Mar como foro para solução pacífica de controvérsias.

O caráter evolutivo do Direito Internacional aplicado ao mar assenta-se não somente no reconhecimento contemporâneo da humanidade, de empresas e de pessoas físicas como sujeitos de Direito Internacional, demonstrando a superação do modelo vestfaliano clássico de dimensão eminentemente interestatal do Direito Internacional, 
como também na consolidação da institucionalização, sistematização e jurisdicionalização do Direito Internacional, destacando-se especificamente o tripé institucional fundamentado na Convenção de Montego Bay. A interpretação do Tribunal Internacional do Direito do Mar encontra-se em consonância com o permanente progresso desse ramo do Direito, possibilitando, inclusive, que usuários do mar possam vir a pleitear indenização junto a este Tribunal em caso de danos ambientais quando da realização das atividades na Área, em um sistema que será constantemente testado, conforme o desenvolvimento das atividades realizadas neste espaço marítimo internacional.

$\mathrm{O}$ referido Tribunal entende pela possibilidade de qualquer Estado-parte da Convenção de Montego Bay pode exigir compensação sob a luz do caráter erga omnes das obrigações relacionadas à preservação do meio ambiente localizado no alto mar e na Área. A consolidação e constante desenvolvimento do princípio do patrimônio comum da humanidade aplicado à Área, tendo a Autoridade dos Fundos Marinhos Internacionais como representante dos respectivos interesses deste sujeito, cuja capacidade de agir encontra-se em status nascendi, consolida a promoção da paz por intermédio do Direito, em um contexto cujas normas jurídicas e tecnologias de exploração encontram-se em constante avanço.

A Autoridade dos Fundos Marinhos Internacionais, por intermédio da Convenção de Montego Bay, do Acordo de 1994 e da respectiva normatização derivada, efetivamente tem representado a humanidade na normatização, organização e controle das atividades realizadas na Área, cabendo à Empresa realizar as referidas atividades de forma direta, ou mesmo em conjunto com demais entidades autorizadas pela Autoridade. E, mesmo que se admita a possibilidade de a Empresa demorar a existir na prática, ou mesmo de ela não vir a ser implementada, considerando o seu atual estágio de institucionalização, o princípio do patrimônio comum da humanidade aplicado à Área resta consolidado perante o Direito Internacional, privilegiando os países em desenvolvimento mediante a possibilidade de acesso às atividades realizadas nessa região marítima internacional, bem como pela distribuição equitativa dos benefícios originados desses recursos.

Frisa-se que antes mesmo da eventual criação da Empresa, os Estados em desenvolvimento já se beneficiam com a aplicação do princípio da cooperação por intermédio da troca de experiências, participação conjunta em projetos, treinamentos, investimentos oriundos da Autoridade dos Fundos Marinhos Internacionais, bem como com a sua atuação junto às "áreas reservadas" e favorecimento com base no fundo de assistência em benefício dos Estados que venham a ser prejudicados pela comercialização 
dos minerais oriundos das atividades realizadas na Área. Especificamente quanto ao caráter ambiental, ressalta-se que as atividades realizadas na Área criam obrigações diretas aos Estados patrocinadores, destacando-se, especificamente, o emprego de uma abordagem de precaução e das melhores práticas ambientais. A abordagem precautória ambiental, já aplicada pelo Tribunal Internacional do Direito do Mar, resta positivada nos regulamentos da Autoridade que tratam da extração dos minérios da Área, consagrando o preceito da precaução, mencionado na Declaração do Rio, com vistas a proteger o meio ambiente marinho de efeitos danosos decorrentes das atividades exercidas na Área. Tal abordagem deve ser aplicada pelos Estados de acordo com suas capacidades, embora as melhores práticas ambientais não sofram qualquer relativização perante o grau de desenvolvimento dos países. Ademais, a aplicação da precaução transforma uma norma principiológica ambiental fundamentada em uma declaração originalmente não obrigatória em uma obrigação vinculativa no contexto do Direito Internacional aplicado às atividades realizadas na Área.

A utilização da Autoridade como foro democrático de discussão de assuntos globais fomenta a produção de normas nacionais sobre as atividades na Área, realizando a interpenetração evolutiva entre o Direito Internacional e o Direito Interno dos países, não sendo diferente no caso do Brasil. Em caso de efetiva criação da Empresa como órgão operacional e comercial da Autoridade, e sua instalação em território brasileiro, ela estará sujeita às leis e à competência dos tribunais brasileiros. Reitera-se que a competência da Câmara de Controvérsias dos Fundos Marinhos do Tribunal Internacional do Direito do Mar é específica para interpretação ou execução de um contrato ou de um plano de trabalho, bem como para atos ou omissões relacionados a um instrumento contratual referente às atividades na Área. A atuação da Empresa no Brasil por intermédio de joint ventures, ou mesmo por intermédio de outros métodos desenvolvidos em respeito à Convenção de Montego Bay e suas normas derivadas, bem como o reconhecimento da Empresa como sujeito de direito interno no Brasil, possibilitarão a sua participação em procedimentos judiciais nos mais diversos temas jurídicos relacionados à sua atuação no país.

A atuação tanto do Brasil como Estado patrocinador na realização das atividades na Área quanto da própria Companhia de Pesquisa de Recursos Minerais, ou mesmo outras entidades que venham a ser patrocinadas pelo país, demonstra o alto grau de inserção do país no contexto da evolução e aplicação do Direito Internacional contemporâneo. Isso faz com que o Brasil enfrente diversos desafios tanto relacionados à realização das atividades 
na Área, quanto concernentes à eventual criação, instalação e atuação da Empresa, como órgão operacional da Autoridade dos Fundos Marinhos Internacionais, em território brasileiro. Assim como o projeto de delimitação das fronteiras brasileiras da Amazônia Azul com a Área deve respeitar as recomendações oriundas da Comissão de Limites da Plataforma Continental com vistas a privilegiar a legalidade e legitimidade fundamentada no Direito Internacional, cabe ao Brasil, também, prestigiar a aplicação do Direito Internacional às atividades realizadas na Área, desenvolvendo normas internas para conciliar suas leis à Convenção de Montego Bay e às suas normas derivadas, inclusive aquelas oriundas da Autoridade dos Fundos Marinhos Internacionais, e à interpretação do Tribunal Internacional do Direito do Mar sobre as atividades na Área. Isto se faz necessário para evitar a responsabilização do Brasil por eventuais danos causados por qualquer falha de entidades por ele patrocinadas na obediência de suas obrigações, desde que o país venha a adotar leis, regulamentos e medidas administrativas que sejam, dentro da estrutura de seu sistema legal, razoavelmente apropriadas para garantir o seu cumprimento pelas pessoas sob sua jurisdição. Ressalva-se a possibilidade de que o país pode, inclusive, vir a ser responsabilizado de forma conjunta e solidária, caso ele não cumpra com suas obrigações fundamentadas no Direito Internacional.

A importância do Direito do Mar na evolução do Direito Internacional restou devidamente comprovada tanto na evolução das normas e dos princípios que regem a matéria - desde antes do contexto vestfaliano - quanto na sua efetiva aplicação por diversos Tribunais Internacionais institucionalizados em diferentes contextos históricos, permeando os órgãos internacionais nos quais a Convenção de Montego Bay se fundamenta, no âmbito contemporâneo do Direito Internacional. Ratifica-se a aplicação do princípio do patrimônio comum da humanidade aos fundos marinhos internacionais, considerando que as características desse princípio restam devidamente consolidadas na contemporaneidade do Direito Internacional, tratando-se de uma cláusula pétrea da Convenção de Montego Bay.

Ressalta-se, especialmente, a sua utilização para fins pacíficos, a não sujeição à soberania estatal, o interesse da humanidade (em especial os Estados em desenvolvimento), a proteção e a preservação do meio ambiente marinho e a existência de uma autoridade internacional responsável pela organização, controle, compartilhamento e administração dos respectivos recursos. Especificamente no que se refere ao alto mar e aos fundos marinhos internacionais, recorda-se que os princípios jurídicos e normas que regem estes espaços marítimos internacionais desenvolveram-se, inicialmente, em contextos 
históricos distintos, sendo que enquanto no primeiro desenvolveu-se o princípio da liberdade dos mares - a qual hoje já sofre diversas restrições de acordo com a Convenção de Montego Bay -, o segundo fundamentou-se na evolução do supracitado princípio do patrimônio comum da humanidade, não se descartando a evolução dos princípios que regem esses espaços com vistas a proteger a humanidade e o meio ambiente. $\mathrm{O}$ funcionamento da Autoridade dos Fundos Marinhos Internacionais na organização e controle das atividades realizadas na Área tem se dado por intermédio de seus órgãos, dos quais emanam as normas derivadas da Convenção de Montego Bay, tendo-se o Tribunal Internacional do Direito do Mar como responsável pela interpretação das respectivas normativas relacionadas às atividades realizadas na Área. Ademais, ainda que em status nascendi, a humanidade encontra na Autoridade uma forma de representação junto ao referido Tribunal, o que demonstra o evolutivo grau de inserção desse sujeito na estrutura jurisdicional do Direito Internacional contemporâneo.

Notadamente quanto à atual situação relativa à efetiva criação da Empresa, embora se admita a sua demora, ou mesmo possibilidade de não vir a ser implementada, a normatização que fundamenta a criação desse órgão operacional da Autoridade demonstra o caráter vanguardista da Convenção da ONU sobre o Direito do Mar de 1982 e de suas normas derivadas, especialmente no que se refere à consolidação do princípio do patrimônio comum da humanidade. Caso a Empresa venha a ser verdadeiramente institucionalizada, haverá implicações, de modo geral, perante o Direito Internacional no que se refere ao tripé institucional embasado na Convenção de Montego Bay, bem como perante o Direito Interno dos países, sendo que caberá ao Brasil adaptar suas normas e instituições à matéria em questão. A própria atuação da Companhia de Pesquisa de Recursos Minerais S/A, tendo o Brasil como Estado patrocinador, tem por base o Direito Internacional como um todo, especificamente a Convenção da Jamaica, o Acordo de 1994 e suas normas derivadas, sujeitando a referida entidade brasileira à relação entre o Direito Internacional e a legislação do país, em um contexto contemporâneo de interpenetração evolutiva e profunda entre ambos ordenamentos jurídicos. As instituições brasileiras enfrentarão diversos desafios decorrentes da realização das atividades na Área, seja pela Empresa, em caso de instalação no país, ou pela referida entidade brasileira já estar autorizada pela Autoridade a exercer essas atividades, considerando a sujeição do Brasil à jurisdição do Tribunal Internacional do Direito do Mar, bem como a interpretação do Poder Judiciário do país no que se refere à relação entre o Direito Internacional e o Direito Interno. 
Considerando o teor da Convenção de Montego Bay e suas normas derivadas, bem como as leis internas brasileiras que regem as atividades realizadas na Área, seja pela Empresa, pela Companhia de Pesquisa de Recursos Minerais, ou mesmo outra entidade, o país deve desenvolver, permanentemente, sua legislação interna com vistas a adaptá-la às normas e regulamentos estabelecidos pela Convenção de Montego Bay e suas normas derivadas. Além disso, o Brasil também deve evoluir constantemente no que se refere ao entendimento, interpretação, compreensão e aplicação do Direito Internacional por seu Poder Judiciário, reiterando-se que as decisões oriundas da Câmara de Controvérsias dos Fundos Marinhos do Tribunal Internacional do Direito do Mar devem ser executórias no país, como se tivessem sido proferidas pelo STF. Destaca-se, portanto, a necessidade de o Brasil desenvolver, de forma permanente, leis e normas procedimentais, objetivando garantir a executoriedade das referidas decisões internacionais.

Destarte, cabe ao Poder Judiciário do Brasil, especialmente representado pelo Supremo Tribunal Federal, retomar o entendimento jurisprudencial histórico que, antes de 1977, evoluía no sentido de consolidação da aplicação do Direito Internacional, consagrando não somente os compromissos internacionais do Brasil expressos nos tratados dos quais ele faz parte, como também princípios que regem o Direito Internacional, evidenciando a característica evolutiva e axiológico-sistêmica que embasa o Direito Internacional contemporâneo. Faz-se relevante, outrossim, a evolução interpretativa do Direito Internacional e sua relação com o Direito brasileiro por parte dos Tribunais do país, bem como pelos juristas, magistrados, legisladores, instituições e demais operadores do Direito. Destarte, o país prestigiará os tratados dos quais faz parte e os compromissos por ele assumidos perante a comunidade internacional, bem como honrará o princípio do patrimônio comum da humanidade, em um processo de acompanhamento do constante progresso civilizatório da comunidade internacional, embasado na promoção da paz por intermédio da primazia do Direito, em um contexto de unidade sistêmica na qual o Direito Internacional e o Direito brasileiro se inter-relacionam.

Considerando a característica de contínua evolução do Direito Internacional que se fundamenta em uma unidade axiológico-sistêmica dentro da qual interage, convive e se inter-relaciona com o Direito Interno dos países, especificamente quanto às atividades realizadas na Área no âmbito do Direito do Mar, caberá às instituições já existentes - tais como o Tribunal Internacional do Direito do Mar, a Autoridade dos Fundos Marinhos Internacionais e o Poder Judiciário brasileiro -, bem como àquelas a serem eventualmente estabelecidas - como é o caso da Empresa -, testar e desafiar toda a sistemática que rege a 
matéria em questão, em um contexto de inter-relação de diversos sujeitos reconhecidos na contemporaneidade. Com isso, estarão contribuindo para o evolutivo desenvolvimento do Direito Internacional e para a consolidação de normas e princípios que regem a sociedade internacional, em um ambiente de constante progresso civilizatório fundamentado na promoção da paz pela primazia do Direito. 


\section{BIBLIOGRAFIA}

ABADE, Denise Neves. Direitos Fundamentais na Cooperação Jurídica Internacional. São Paulo: Saraiva, 2013.

ABASS, Ademola. International Law. Text, cases and materials. $2^{\text {nd }}$ ed. Oxford: Oxford University Press, 2014.

ALMEIDA, Paulo Roberto de. 1492 e o nascimento da moderna diplomacia. VI Encontro Regional de História. Junta Regional de História e Estudos Conexos. Montevidéu, 21-23 set. 1991, pp. 1-24.

ANAND, R.P. Origin and development of the Law of the Sea. History of International Law Revised. The Hague/Boston/London: Martinus Nijhoff Publishers, 1983, p. 10.

AUBURN, F.M. The International Seabed Area. International and Comparative Law Quarterly, 1971, v. 20.

BAI, Young; BAI, Qiang. Subsea Engineering Handbook. London: Elsevier, 2010.

BAILEY, John S. The future of the exploitation of the resources of the deep seabed and subsoil. Law and Contemporary Problems. Durham, Spring 1983, v. 46, n. 2, p. 73.

BARDONNET, Daniel. Le projet de Convention de 1912 sur le spitsberg et le concept de Patrimoine Commun de 1'Humanité. Humanité et Droit International. Mélanges RenéJean Dupuy. Paris: A. Pedone, 1991, pp. 13-34.

BASLAR, Kemal. The concept of common heritage of humankind in International Law. Kluwer Law International. The Hague. Netherlands: Martinus Nijhoff Publishers, 1998.

BATISTA, Nicolá Navarro. Fondos Marinos y Património Común de la Humanidad. Salamanca: Ed. Universidad Salamanca, 2000.

BEIRÃO, André Panno. PEREIRA, Antônio Celso Alves (Org.). Reflexões sobre o Direito do Mar. Fundação Alexandre de Gusmão. Brasília, 2014.

BELLO, Andrés. Princípios de Derecho Internacional. 3. ed. Clichy, 1873.

BERKOWITZ, Abraham. John Selden and the biblical origins of the modern International Political System. Jewish Political Studies Review. Spring 1994, v. 6, n. 1-2.

BENVENISTI, Eyal. The conception of International Law as a legal system. German Yearbook of International Law. Berlin: Duncker \& Humblot, 2008, v. 50, pp. 390-405.

BORGESE, Elisabeth Mann (Ed.). Pacem in Maribus. New York: Dodd, Mead \& Company. New York. 1972.

BRASIL. Constituição da República Federativa do Brasil. Inteiro teor disponível em: http://www.planalto.gov.br/ccivil_03/constituicao/ConstituicaoCompilado.htm. Acesso em: 4 abr. 2016. 
Decreto $n^{0}$ 6.728, de 12 de janeiro de 2009. Promulga o Protocolo sobre Privilégios e Imunidades da Autoridade dos Fundos Marinhos Internacionais, assinado em Kingston, em 27 de agosto de 1998. Art. 14. Disponível em: http://www.planalto.gov.br/ccivil_03/_Ato2007-2010/2009/Decreto/D6728. htm. Acesso em: 29 maio 2016.

Decreto $n^{0}$ 1.530, de 22 de junho de 1995. Declara a entrada em vigor da Convenção das Nações Unidas sobre o Direito do Mar, concluída em Montego Bay, Jamaica, em 10 de dezembro de 1982. Disponível em: http://www.planalto.gov.br/ccivil_03/decreto/1995/D1530.htm. Acesso em: 29 maio 2016.

Lei $\mathrm{n}^{\circ}$ 8.617, de 4 de janeiro de 1993. Dispõe sobre o mar territorial, a zona contígua, a zona econômica exclusiva e a plataforma continental brasileiros, e dá outras providencias. Diário Oficial [da] Republica Federativa do Brasil, Brasília, DF, 05/01/1993. Disponível em: http://www.planalto.gov.br/ccivil_03/leis/18617.htm. Acesso em: 10/10/2013.

BROWN, Henry B. The proposed international prize court. The American Journal of International Law. Published by the American Society of International Law Stable, jul. 1908, v. 2, n. 3.

BURKE, Robert. The law and regulations of mining. Minerals to Energy. Durham: Carolina Academic Press, 2010.

BYNKERSHOEK, Cornelius van. De Dominio Maris Dissertatio. A photographic reproduction of the second edition (1744). English Translation by Ralph Van Deman Magoffin. New York: Oxford University Press, 1923.

CAMINOS, Hugo. United Nations. The legal régime of straits in the 1982. Convention on the Law of the Sea. Recueil des Cours, 1987-V, v. 205.

CAMPBELL, Dennis. The comparative Law Yearbook of International Business. Special Issue. Salzburg: Kluwer Law International, 2008.

CARMONA, Carlos Alberto. Arbitragem e Processo. Um comentário à Lei n ${ }^{\circ}$ 9.307/96. 3. ed. São Paulo: Atlas, 2009.

CARRINGTON, C.E. The British Overseas. Exploits of a nation of shopkeepers. $2^{\text {nd }}$ ed. Cambridge University Press. Cambridge, 1968.

CASELLA, Paulo Borba. Fundamentos e Perspectivas do Direito Internacional pósmoderno. São Paulo: Quartier Latin, 2008.

Direito Internacional dos Espaços. São Paulo: Atlas, 2009.

; ACCIOLY, Hildebrando; NASCIMENTO E SILVA, G.E. Manual de Direito Internacional Público. São Paulo: Saraiva, 2012.

CASTRO, Luiz Augusto de Araújo. O Brasil e o Novo Direito do Mar. Mar Territorial e Zona Econômica Exclusiva. Brasília: Fundação Alexandre de Gusmão. Instituto de Pesquisa de Relações Internacionais-IPRI, 1989 
CENTRO DE HISTÓRIA E DOCUMENTAÇÃO DIPLOMÁTICA. II Conferência da Paz, Haia, 1907: a correspondência telegráfica entre Barão do Rio Branco e Rui Barbosa. Brasília: FUNAG, 2014.

CHO, Yoona. Precautionary Principle in the International Tribunal for the Law of the Sea. Sustainable Development Law \& Policy. Washington, 2009, v. 10, Issue 1.

CHURCHILL, R. R.; LOWE, A.V. The Law of the Sea. Manchester: Manchester University Press, 1983.

COMISSÃO INTERMINISTERIAL PARA OS RECURSOS DO MAR. Programa de Prospecção e Exploração de Recursos Minerais da Área Internacional do Atlântico Sul e Equatorial (PROAREA). Brasília, 2009.

COSTA DE SOUZA, Henrique Santos. O fundamento do Direito Internacional Contemporâneo: o ser humano e suas dimensões. In: MENEZES, Wagner (Org.). Direito Internacional Contemporâneo e seu fundamento. Belo Horizonte: Arraes, 2014, v. 1.

A imensidão azul e a Declaração do Milênio In: MENEZES, Wagner et al. (Org.). Direito Internacional em expansão. Belo Horizonte: Arraes Eds, 2014, v. III.

A Convenção das Nações Unidas sobre o Direito do Mar e a obrigação de cooperação. Revista de la Secretaría del Tribunal Permanente de Revisión - RSTPR. Mercosur: Asunción, 2015, año 3, n. 6.

CPRM. Serviço Geológico do Brasil. Relatório Anual 2014. Ministério de Minas e Energia. Brasília, 2015.

CRAIG, Robin Kundis. Comparative Ocean Governance. Place-based protections in an era of climate change. Cheltenham, United Kingdom: Edward Elgar Publishing Ld, 2012.

DIHN, Nguyen Quoc; DAILLIER, Patrick; PELLET, Alain. Droit International Public. Paris: LGDJ, 6. éd., 1999.

DUPUY, Pierre-Marie. Humanité, Communauté et Efficacité do Droit. Mélanges RenéJean Dupuy. Paris: A. Pedone, 1991.

L'unité de l'ordere juridique international: cours général de droit international public. RCADI, 2002, t. 297.

DUPUY, René-Jean. Droit de la mer et Communauté Internationale: mélanges offerts a Paul Reuter. Le Droit International: unité et diversité. Paris: A. Pedone, 1981, p. 241.

. La notion de Patrimoine Commun de l'Humanité appliqué aux Fonds Marin. Droit et Libertés à la fin du XX Siècle. Influence des Donées Économiques et Tecnologiques. Études Offertes à Claude-Albert Colliard. Paris: A. Pedone, 1984.

; VIGNES, Daniel (Eds.). A Handbook on the New Law of the Sea. DordrechtBoston-Lancaster: Martinus Nijhoof Publishers, 1991. 
EVENSEN, Jens. Keynote Address. In: KOERS, A.; OXMAN, B. (Eds.). The 1982 Convention on the Law of the Sea. Proceedings of the Seventeenth Annual Conference of the Law of the Sea Institute. Honolulu, 1984.

FIGUEIRÔA, Christiano S. B.; DUTRA, JR, Aniel Eller; COSTA, Felipe A. R. A.; MORAES, Lanier G.; CARDOSO, Rodrigo A. Direito dos Fundos Marinhos Internacionais: o Patrimônio Comum da Humanidade 20 anos após a Convenção de Montego Bay. In: TRINDADE, Antônio Augusto Cançado (Org.). A Nova Dimensão do Direito Internacional Público. Brasília: Instituto Rio Branco, 2003.

FONTOURA, Jorge. O descortino da obra de Marotta Rangel em face das demandas do pré-sal. In: MENEZES, Wagner (Org.). Direito do Mar: desafios e perspectivas. Belo Horizonte: Arraes, 2015.

FRANCKX, Erik. The International Seabed Authority and the Common Heritage of Mankind: the need for states to establish the outer limits of their continental shelf. The International Journal of Marine and Coastal Law. Leiden: Martinus Nijhoff Publishers, 2010, v. 25.

FRAZÃO, Ana. Joint Ventures contratuais. RIL. Brasília, ano 52, jul./set. 2015, n. 207, pp. 187-211.

FULTON, Thomas Wemyss. The Sovereignty of the Sea. An historical account of the claims of England to the dominion of the british seas, and of the evolution of the territorial waters: with special reference to the Rights of Fishing and the Naval Salute. Edinburg and London: William Blackwood and Sons, 1911.

GALIANI, Ferdinando. De' Doveri de' Principi Neutrali verso i Principi Guerreggianti, e di Questi verso i Neutrali. Libri due. Napoli, 1782.

GEROMEL, Vitor. Jurisdição Internacional e Justiça Brasileira: harmonias e dissonâncias. Belo Horizonte: Arraes, 2015, p. 69.

GHOSH, Anil K.; MUKHOPADHYAY, Ranadhir. Mineral Wealth of the Ocean. A treatise on distribution, origin, exploration, mining and management of sea floor non-living resources. Rotterdam: A.A.Balkema, 2000, pp. 176-204.

GOLITSYN, Vladimir. Continental shelf claims in the Arctic Ocean: a commentary. The International Journal of Marine and Coastal Law. Martinus Nijhoff Publishers, 2009, v. 24.

GREENPEACE. The need for a High Seas Biodiversity Agreement. JN 415. Second Edition. Greenpeace International. Amsterdam, 2013.

GRÓCIO, Hugo. O Direito da Guerra e da Paz (De Jure Belli ac Pacis, 1625). Ijuí, RS: Ed. da Unijuí, 2005, v. 1.

GROSS, Leo. New rules and institutions for the Peaceful Settlement of International Disputes. American Society of International Law Proceedings. [s.l.; s.d.], v. 76. 
GUNTRIP, Edward. The common heritage of mankind. An adequate regime for managing the deep seabed? Melbourne Journal of International Law. Melbourne, October 2003, v. 4, n. 1 .

HALDAR, S.K. Mineral Exploration. Principles and applications. London: Elsevier, 2013.

HARTMAN, Howard L.; MUTMANSKY, Jan M. Introductory Mining Engineering. $2^{\text {nd }}$ ed. John Wiley \& Sons, 2002.

HOOF, G.J.H. Legal status of the concept of the common heritage of mankind. Grotiana, 1986, v. 7, n. 1.

HUDSON, Manley O. Les avis consultatifs de la Cour Permanente de Justice Internationale. RCADI, 1925-III, t. 8.

. International Tribunals: past and future. Washington D.C.: Carnegie Endowment for International Peace and Brookings Institution, 1944.

INTERNATIONAL COURT OF JUSTICE. S.S. Wimbledon (1923). P.C.I.J. (Ser.A). N.1

S.S. Lotus. (1927). P.C.I.J. (Ser. A). N.10.

Corfu Channel (United Kingdom of Great Britain and Northern Ireland v. Albania), 9 apr. 1949. April 1949.

Reparation for Injuries Suffered in the Service of the United Nations, 11

Legal consequences for states of the continued presence of South Africa in Namibia (South West Africa). Notwithstanding Security Council Resolution 276 (1970). 21 June 1971.

Pulp Mills on the River Uruguay (Argentina v. Uruguay). 20 April 2010, paragraph 205. March 2014.

Whaling in the Antarctic (Australia v. Japan: New Zealand intervening). 31

INTERNATIONAL LAW COMISSION. Draft articles on responsibility of states for internationally wrongful acts, with commentaries. Yearbook of the International Law Commission, 2001, v. II, Part two.

INTERNATIONAL SEABED AUTHORITY. Legal and Technical Commission. Issues relating to the operation of the enterprise, in particular the legal, technical and financial implications for the authority and for states parties. ISBA/22/LTC/9. Twenty-Second Session. Kingston, Jamaica, April 2016.

Report and recommendations of the Legal and Technical Commission to the Council of the International Seabed Authority relating to an application for the approval of a plan of work for exploration for cobalt-rich ferromanganese crusts by Companhia de Pesquisa de Recursos Minerais. ISBA/20/C/17. 20th Session, Kingston, Jamaica. 14-25 July 2014. 
Application for approval of a plan of work for exploration for cobalt-rich ferromanganese crusts by the Companhia de Pesquisa de Recursos Minerais S/A. Legal and Technical Commission. ISBA/20/LTC/2. Twentieth Session. Kingston, Jamaica, 14-25 July 2014.

Decision of the council relating to an application for the approval of a plan of work for exploration for cobalt-rich ferromanganese crusts by Companhia de Pesquisa de Recursos Minerais. ISBA/20/C/30. Council. Kingston, Jamaica, 21 July 2014.

The International Seabed Authority Structure and Functioning. Kingston, Jamaica: International Seabed Authority. Kingston, Jamaica, May-2014.

Recommendations for the guidance of contractors for the assessment of the possible environmental impacts arising from exploration for marine minerals in the Area. ISBA/19/LTC/8. Kingston, Jamaica, 2013.

Regulations on prospecting and exploration for cobalt-rich ferromanganese crusts in the Area. ISBA/16/C/WP.2. Regulation 1. Kingston, Jamaica, 29 November 2009.

Implementation of the Article 82 of the United Nations Convention on the Law of the Sea. ISA Technical Study: N. 12. Kingston, Jamaica, 2012.

. Decision of the council relating to an Environmental Management Plan for the Clarion-Clipperton Zone. Council, ISBA/18/C/22. Kingston, Jamaica, 2012.

. Basic Texts. $2^{\text {nd }}$ ed. Kingston, Jamaica. 2012.

. Decision of the Council of the International Seabed Authority. ISBA/17/C/20. Kingston, Jamaica, 11-22 July 2011.

Non-living resources of the Continental Shelf Beyond 200 nautical miles: speculations on the implementation of article 82 of the United Nations Convention on the Law of the Sea. International Seabed Authority Technical Study. Kingston, Jamaica, 2010, n. 5.

Council Sixteenth Session. ISBA/16/C/6 and ISBA/16/C/13. Kingston, Jamaica. 26 April - 7 May 2010.

A summary of Available Information in the Public Domain on the Likely Impact of Exploration and Mining Activities for Nodules on the Marine Environment. International Seabed Authority, Kingston, Jamaica, 26 August 2010.

. Regulations on prospecting and exploration for polymetallic sulphides in the Area. ISBA/16/A/12/Rev.1. Regulation 18(1), Kingston, Jamaica, 2010.

Legal and Technical Commission. ISBA/15/LTC/6*. Fifteenth session. Kingston, Jamaica, 25 Mayo - 5 June 2009. 
Regulations on Prospecting and Exploration for Cobalt-rich Ferromanganese Crusts in the Area. ISBA/16/C/WP.2. Kingston, Jamaica, 29 November 2009. 2008.

Council. ISBA/14/C/8. Fourteenth session. Kingston, Jamaica, 26 Mayo - 6 June

Legal and Technical Commission. ISBA/14/LTC/L.2. Fourteenth session. Kingston, Jamaica, 26 Mayo - 6 June 2008.

Deep seabed mineral development, bio-prospecting and the protection of biological diversity in the deep seabed and on the high seas. Kingston, Jamaica, April 2002.

Legislative history of the "Enterprise" under the United Nations Convention on the Law of the Sea and the Agreement relating to the Implementation of Part XI of the Convention. Kingston, Jamaica, 2002.

Regulations on prospecting and exploration for polymetallic nodules in the Area. ISBA/16/A/Rev.1. Regulation 17(1), Kingston, Jamaica, 2000.

Council. Decision of the Council of the Authority concerning the Rules of Procedure of the Legal and Technical Commission. ISBA/6/C/9. Kingston, Jamaica, 13 July 2000. Rules 6 and 53.

Pollymetalic Nodules. Jamaica: Kingston, 2000.

INTERNATIONAL TRIBUNAL FOR THE LAW OF THE SEA. Disputes considering delimitation of the Maritime boundary between Ghana and Côte D'Ivoire in the Atlantic Ocean. Case 23, Provisional Measures. Hamburg, Germany, Order of 25 April 2015.

Statement by H. E. Vladimir Golitsyn, President of the International Tribunal for the Law of the Sea on the Report of the Tribunal at the Twenty-Fifth Meeting of States Parties to the United Nations Convention on the Law of the Sea. Hamburg, Germany, 8 June 2015.

M/V "Virginia G" case. Panama/Guinea-Bissau. Judgment. ITLOS Reports. Hamburg, Germany, 14 April 2014.

The Arctic Sunrise Case (Kingdom of Netherlands v. Russian Federation). Case 22. Provisional Measures. Hamburg, Germany, 22 November 2013.

The ARA Libertad case (Argentina v. Ghana). Hamburg, Germany, Order 15 December 2012.

Responsibilities and obligations of States sponsoring persons and entities with respect to activities in the Area (Request for Advisory Opinion submitted to the Seabed Disputes Chamber). Advisory Opinion. Case n. 17. Hamburg, 1 February 2011.

. M/V "Loiusa" (Saint Vincent and the Grenadines v. Kingdom of Spain), case 18. Provisional Measures. Hamburg, Germany, 23 December 2010. 
Case concerning the conservation and sustainable exploitation of swordfish stocks in the South-Eastern Pacific Ocean. Case n. 7. Hamburg, Germany, 16 December 2009.

. M/V SAIGA (Case n. 2). Saint Vincent and the Granadines v. Guinea). Judgment. ITLOS Reports. Hamburg, Germany, 1 July 1999.

Southern Bluefin Tuna Cases (New Zealand v. Japan; Australia v. Japan), Provisional Measures. Cases 3 \& 4. Hamburg, Germany, 27 August 1999.

JAGOTA, S.P. Maritime Boundary. Recueil des Cours, 1981-II, v. 171.

JESSUP, Ph. C. L'exploration des richesses de la mer. Recueil des Cours, 1929-IV, v. 29.

JO, Hee Moon. Introdução ao Direito Internacional. 2. ed. São Paulo: LTr, 2004.

KISS, Alexandre-Charles. La notion de Patrimoine Commun de l'Humanité. Recueil des Cours. The Hague Academy of International Law. London: Martinius Nijhoff Publishers, 1982.

$\mathrm{KOH}$, Tommy T.B. A Constitution for the Oceans. United Nations Convention on the Law of the Sea. UN Pub. Sales, n. E. 1983, v. 5.

KOROMA, Abdul G. Implementation of the law of the Sea Convention Through its Institutions: an overview. In: VIDAS, Davor; OSTRENG, Willy. Order for the Oceans at the turn of the century. Kluwer Law International. The Hague, 1999.

LA PRADELLE, Albert de Geoufre de. Le droit de l'etat sur la mer territoriale. In: PILLET, Antoine; FAUCHILLE, Paul (Orgs). Revue Générale de Droit International Public: droit de gens, histoire diplomatique, droit pénal, droit fiscal, droit administratif. Paris: A. Pedone, 1898.

LEITE, Guilherme; RODRIGUES, Talita Alves. Brazil. In: CAMPBELL, Dennis (Org.). The comparative law yearbook of International Business. Special Issue. Kluwer Law International. Salzburg, 2008.

LEVY, Jean-Pierre. Le destin de l'Autorité Internationale des Fonds Marins. Paris : A. Pedone, 2002,

LIMA, Sérgio Eduardo Moreira. Apresentação. In: BEIRÃO, André Panno; PEREIRA, Antônio Celso Alves (Orgs.). Reflexões sobre a Convenção do Direito do Mar. Brasília: Fundação Alexandre de Gusmão, 2014.

LODGE, Michael W. Current legal developments international seabed authority. The International Journal of Marine and Coastal Law, 2009, v. 24.

Current legal developments. International Seabed Authority. International Journal of Marine and Coastal Law. Martinus Nijhoff Publishers, 2011, v. 26, issue 3.

Satya Nandan's Legacy for the Common Heritage of Mankind. Peaceful Order in the World's Oceans. Essays in Honor of Satya N. Nandan. Leiden: Brill Nijhoff, 2014. 
A Autoridade dos Fundos Marinhos Internacionais, as atividades realizadas na Área, a Empresa e a contemporaneidade (Entrevista concedida em Kingston, Jamaica, em 16 de setembro de 2015).

. The deep seabed. In: ROTHWELL, Donald et al. (Ed.). The Oxford Handbook of the Law of the Sea. Oxford: Oxford University Press, 2015.

MACHADO, Nilson José. Educação e Autoridade. Responsabilidade, limites, tolerância. Petrópolis, RJ: Vozes, 2008.

MARCHANT, James Robert Vernam. Cassell's Latin Dictionary. Latin-English and English Latin. London, Paris, New York, Melbourne: Cassell and Company Limited, 1904, pp. 395-396.

MARKY, Thomas. Curso elementar de direito romano. 8. ed. São Paulo: Saraiva, 1995.

MATTOS, Adherbal Meira. Os novos limites dos espaços marítimos nos trinta anos da Convenção das Nações Unidas sobre o Direito do Mar In: BEIRÃO, André Panno; PEREIRA, Antônio Celso Alves (Orgs.). Reflexões sobre a Convenção do Direito do Mar. Brasília: Fundação Alexandre de Gusmão, 2014.

MENEZES, Wagner. Ordem Global e Transnormatividade. Ijuí, RS: Ed. Unijuí, 2005.

. Tribunais Internacionais: Jurisdição e Competência. São Paulo: Saraiva, 2013.

Tribunal Internacional do Direito do Mar e sua contribuição jurisprudencial. In: BEIRÃA, André Panno; PEREIRA, Antônio Celso Alves (Orgs.). Reflexões sobre a Convenção do Direito do Mar. Brasília: Fundação Alexandre de Gusmão, 2014.

O Direito do Mar. Brasília: Fundação Alexandre de Gusmão, 2015.

Direito do mar: desafios e perspectivas. Belo Horizonte: Arraes, 2015.

MENSAH, Thomas A. International Tribunal for the Law of the Sea and the Private Maritime Sector. International Business Lawyer. July-August 1999.

MERO, J. L. The Mining and Processing of Deep-sea Manganese Nodules. Berkley, California: Institut of Marine Resources, 1959.

MILLER, Robert R. et al. International Joint Ventures in Developing Countries: Happy Marriages? International Finance Corporation. Discussion Paper n. 29. Washington: The World Bank, 1996.

MOON, Charles J.; WHATELEY, Michael K.G.; EVANS, Anthony M. Introduction to Mineral Exploration. $2^{\text {nd }}$. ed. Oxford: Blackwell Publishing, 2006.

MORETTI, Juliano Lazzarini; PIAGENTINI, Luiz Guilherme de Souza. Mineração nos leitos oceânicos, uma nova tendência? In: MENEZES, Wagner (Org.). Direito do mar. Desafios e perspectivas. Em homenagem a Vicente Marotta Rangel. Belo Horizonte: Arraes, 2015. 
MUKHERJEE, Proshanto K. Enhancement of Maritime Law Education in the Indian context. NUJS Law Review, v. 383, oct./dec. 2010.

MYRDAL, Alva. No arms on the Ocean Floor. In: BORGESE, Elisabeth Mann (Ed.). Pacem in Maribus. New York: Dodd, Mead \& Company, 1972.

NANDAN, Satya N.; LODGE, Michael W.; ROSENNE, Shabtai (General Editor). The Development of the Regime for Deep Seabed Mining. The Hague. Kluwer Law International, 2002.

NÉGULESCO, Démètre. L'evolution de la Procédure des Avis Consultatifs de la Cour Permanente de Justice Internationale. RCADI, 1936-III, t. 57, pp. 78-80, 92-93.

NELSON, Jason C. The contemporary seabed mining regime: a critical analysis of the mining regulations promulgated by the International Seabed Authority. Colorado Journal of International Environmental Law \& Policy, 2005, v. 16, n. 1, p. 28.

NELSON, L.D.M. The Emerging New Law of the Sea. The Modern Law Review. Vol. 42. 1979.

The new deep sea-bed mining regime. The International Journal of Marine and Coastal Law. Graham \& Trotman Limited, 1995, v. 10, n. 2, p. 196.

NGUYEN QUOC, Dihn; DAILLIER, Patrick; PELLET, Alain. Droit International Public. 6. ed. Paris: LGDJ, 1999.

OCTAVIANO MARTINS, Eliane M.; LUPATELLI JÚNIOR, Alfredo. Joint Ventures e a defesa da concorrência no Brasil. Boletim Latinoamericano de Competência. DGIV, maio 1999, v. 1, n. 6.

Curso de Direito Marítimo. 3. ed. Barueri, SP: Manole, 2008, v. I.

. Parcerias empresarias e “Joint Ventures”. Âmbito Jurídico, 2009, v. 69.

\section{III.}

Curso de direito marítimo. Contratos e processos. Barueri, SP: Manole, 2015, v.

ODA, Shigeru. International law of the resources of the sea. Recueil de Cours, 1969-II, v. 127.

Future Regime of the Deep Ocean Floor. Proceedings of the Symposium on the International Regime of the Sea-Bed. Accademia Nazionale dei Lincei. Instituto Affan Internazíonali. Rome, 1970.

. The International Court of Justice. Recueil des Cours. 1993-VII. DordrechtBoston-London: Martinus Nijhoff Publishers, 1995.

ODUNTON, Nii Allotey. The International Seabed Authority. Structure and functions. Kingston: International Seabed Authority, February, 2012. 
OILFIELD PUBLICATIONS LIMITED. Offshore Drilling \& Production Concepts of the World. Formerly Field Development Concepts of the World. $5^{\text {th }}$ Ed. Oilfield Publications Limited. Ledbury, 2002-2003.

ORTOLLAND, Didier; PIRAT, Jean-Pierre. Atlas Géopolitique des Espaces Maritimes. Frontières, Énergie, Transports, Piratarie, Pêche et Environnement. 2. éd. Paris: Editions Technip, 2010.

OXMAN, Bernard H. The 1994 agreement relating to the implementation of the Part XI of the UN Convention on the Law of the Sea. In: VIDAS, Davor; OSTRENG, Willy. Order for the Oceans at the Turn of the Century. The Hague: Kluwer Law International, 1999.

PAIM, Maria Augusta. A expansão da Amazônia Azul: a plataforma continental do Brasil além das 200 milhas náuticas. In: PEREIRA, A.C.A.; PEREIRA, J.E.A. (Orgs). Reflexões sobre a Convenção do Direito do Mar. Brasília: FUNAC, 2014.

PARDO, Arvid. An International Regime for the Deep Seabed: Developing Law or Developing Anarchy? Texas International Law Forum, 1969-1970, v. 5, n. 2.

PARK, Seong Wook. Key Issues on the Commercial Development of Deep Seabed Mineral Resources. Paper from the Law of the Sea Institute. UC Berkeley-Korea Institute of Ocean Science and Technology Conference. Seoul, Korea, may, 2012.

PEREIRA, Antônio Celso Alves; PEREIRA, João Eduardo de Alves. A Liberdade do Alto-Mar - Antecedentes históricos dos artigos de 87 a 90 da Convenção das Nações Unidas sobre o Direito do Mar. In: BEIRÃO, André Panno; PEREIRA, Antônio Celso Alves (Orgs.). Reflexões sobre o Direito do Mar. Brasília: Fundação Alexandre de Gusmão, 2014.

PILLET, Antoine; FAUCHILLE, Paul (Org.). Revue Générale de Droit International Public: droit de gens, histoire diplomatique, droit pénal, droit fiscal, droit administratif. Paris: A. Pedone, 1898.

PINTO, Felipe Flores. Tradição e modernidade na obra de Hugo Grócio. In: TRINDADE, Antônio Augusto Cançado (Org.). A Nova Dimensão do Direito Internacional Público. Brasília: Instituto Rio Branco, 2003, v. I.

PINTO, M.C.W. The common heritage of mankind: then and now. Recueil de Cours, 2012, v. 361, n. 9.

PIOVESAN, Flávia. Direitos Humanos e o Direito Constitucional Internacional. 13. ed. São Paulo, 2012.

POISEL, Tim. Deep seabed mining: implications of seabed disputes chamber's advisory opinion. Australian International Law Journal. Sydney, 2012.

PUFENDORF, Samuel. De Jure Naturae et Gentium Libri Octo. Tradução da Edição de 1688. Oxford: Clarendon Press; London: Humphrey Milford, 1934, v. II.

QUÉNEUDEC, Jean-Pierre. Chronique du Droit de la Mer. Annuaire Français de Droit International, 1988, v. 34. 
RAMOS, André de Carvalho. Direitos Humanos em Juízo: comentários aos casos contenciosos e consultivos da Corte Interamericana de Direitos Humanos e o estudo da implementação dessas decisões no Direito brasileiro. São Paulo: Max Limonad, 2001.

Pluralidade das ordens jurídicas: uma nova perspectiva na relação entre o Direito Internacional e o Direito Constitucional. Revista da Faculdade de Direito da Universidade de São Paulo. São Paulo. Jan-Dez 2011-2012, v. 106-107.

O novo Direito Internacional privado e o conflito de fontes na cooperação jurídica internacional. Revista da Faculdade de Direito (USP). São Paulo, 2013, v. 108, p. 639.

RANGEL, Vicente Marotta. Questões metodológicas em Direito Internacional Público. Revista da Faculdade de Direito da Universidade de São Paulo. São Paulo, 1960, v. 55.

. Brazilian Law of the Sea. Revista da Faculdade de Direito da Universidade de São Paulo. São Paulo, 1970, v. 68, n. 1.

A Corte Internacional de Justiça e o Direito do Mar. Revista da Faculdade de Direito da Universidade de São Paulo, 1976, v. 71.

O novo Direito do Mar e a América Latina. Revista da Faculdade de Direito da Universidade de São Paulo. São Paulo, 1982, v. 77, p. 105.

A problemática da Zona Econômica Exclusiva: vamos perder as 200 milhas? Revista da Faculdade de Direito da Universidade de São Paulo. São Paulo, jan.1995, v. 90 .

Conflitos de leis marítimas: questões prévias. Revista da Faculdade de Direito da Universidade de São Paulo. São Paulo, 1996, v. 91.

Jurisdição Internacional: considerações preambulares. In: RAMOS, Rui Manoel de Moura et al. (Org.). Estudos em homenagem à professora Isabel de Magalhães Collaço. Coimbra, Portugal: Almedina, 2002, v. 2

Settlement of Disputes Relating to the Delimitation of the Outer Continental Shelf: The Role of the International Courts and Arbitral Tribunals. The International Journal of Marine and Coastal Law. Koninklijke Brill NV, 2006, v. 21, n. 3.

Homenagem ao Prof. Emérito Vicente Marotta Rangel - O múltiplo retorno. Revista da Faculdade de Direito da Universidade de São Paulo. Jan/Dez 2006, v. 101.

Direito e Relações Internacionais. Legislação internacional anotada. 9. ed. São Paulo: Revista dos Tribunais, 2010.

2012, n. 95 .

Regime jurídico de exploração do pré-sal. Revista USP. São Paulo, set./out./nov. 
Fundos oceânicos. In: BEIRÃO, André Panno; PEREIRA, Antônio Celso Alves

(Orgs.). Reflexões sobre a Convenção do Direito do Mar. Brasília: Fundação Alexandre de Gusmão, 2014.

RIBEIRO, Patrícia Henriques. As Relações entre o Direito Internacional e o Direito Interno. Conflitos entre o ordenamento brasileiro e as normas do Mercosul. Belo Horizonte: Del Rey, 2001

ROCHA, Karine Maria Famer. Autoridade Internacional dos Fundos Marinhos e Empresa. Análise da Organização Internacional e seu Órgão Operativo criados pela Convenção das Nações Unidas sobre Direito do Mar de 1982. Dissertação (Mestrado em Direito Internacional) - Faculdade de Direito da Universidade de São Paulo. São Paulo, 2003.

RODRIGO, Ángel J.; GARCIA, Caterina (Eds.). Unidad y pluralismo en el Derecho Internacional Público y en la comunidad internacional. Coloquio en Homenaje a Oriol Casanovas, 21-22 de mayo de 2009. Madrid: Tecnos, 2011.

ROLIM, Maria Helena Fonseca de Souza. A Convemar e a proteção do meio ambiente marinho: impacto na evolução e codificação do Direito do Mar. As ações implementadas pelo Brasil e seus reflexos no Direito Nacional. In: BEIRÃO, André Panno; PEREIRA, Antônio Celso Alves (Orgs.). Reflexões sobre a Convenção do Direito do Mar. Brasília: Fundação Alexandre de Gusmão, 2014.

ROTHWELL, Donald R. et al. Charting the future for the Law of the Sea. In: ROTHWELL, Donald R. et al (Eds.). The Oxford Handbook of the Law of the Sea. Oxford: Oxford University Press, 2015.

SCOVAZZI, Tullio. The evolution of International Law: new issues, new challenges. Recueil des Cours, 2000, v. 286.

SELDEN, John. Of the dominion, or, ownership of the Sea (Mare Clausum seu, De Dominio Maris, 1635). Translated into English by Marchamont Nedham. New Jersey: The Lawbook Exchange Ltd. Clark, 2004.

SÉROUSSI, Roland. Introdução ao Direito Inglês e Norte-Americano. São Paulo: Landy, 2001.

SHAW, Malcolm N. International Law. $6^{\text {th }}$ ed. Cambridge, 2008, p. 553.

SOUZA, Kaiser. G. de. Recursos minerais marinhos além das jurisdições nacionais. Brazilian Journal of Geophysics, 2000, v. 18, n. 3.

Relatório de Viagem ao Exterior. Jamaica, Kingston. XIII Sessão da Autoridade Internacional dos Fundos Marinhos (ISBA). Ministério de Minas e Energia. Secretaria de Geologia, Mineração e Transformação Mineral. CPRM - Serviço Geológico do Brasil. Brasília, 2007.

THAKUR, Ramesh (Ed.). What is equitable geographic representation in the twentyfirst century. Report of a seminar held by the International Peace Academy and the United 
Nations University on 26 March 1999. New York, USA, The United Nations University. Tokyo, 1999.

TREVES, Tullio; PINESCHI, Laura (Eds.). The Law of the Sea. The European Union and its Member States. The Hague, Boston, London: Martinus Nijhoff Publishers, 1997.

Geneva Conventions on the Law of the Sea [1958]. Audiovisual Library of International Law, 2008.

TRINDADE, Antônio Augusto Cançado. O Direito Internacional em um mundo em transformação. Ensaios 1976-2001. Rio de Janeiro: Renovar, 2002.

(Org.) A Nova Dimensão do Direito Internacional público. Brasília: Instituto Rio Branco, 2003, v. 1.

International Law for Humankind: towards a New Jus Gentium. Hague Academy of International Law, 2006, v. I.

. International Law for Humankind: towards a New Jus Gentium. Hague Academy of International Law, 2006, v. II.

Os Tribunais Internacionais Contemporâneos. Brasília: Fundação Alexandre de Gusmão, 2013.

TUERK, Helmut. The contribution of the International Tribunal for the Law of the Sea to International Law. Penn State International Law Review, 2007-2008, v. 26, n. 2.

UNITED KINGDOM OF GREAT BRITAIN AND NORTHERN IRELAND. Deep Sea Mining Act 2014. The Stationary Office. Norwich, 2014.

UNITED NATIONS. United Nations Convention on the Law of the Sea. 10 december 1982.

Resolution 2740 (XXV) of the General Assembly of the United Nations. Declaration of Principles Governing the Sea-Bed and the Ocean Floor, and the Subsoil Thereof, beyond the Limits of National Jurisdiction.

. General Assembly. Resolution A/RES/48/263. 28 July 1994.

Resolution 1.514 (XV) of the General Assembly of the United Nations. 14 December 1960.

Oceans: the surce of life. United Nations Convention for the Law of the Sea $20^{\text {th }}$ Anniversary (1982-2002), 2002.

United Nations General Assembly. Twenty Second Session. Official Records. First Committee. $1515^{\text {th }}$ meeting. New York. 1 November 1967.

UNESCO. United Nations Educational, Scientific and Cultural Organization. Hundred and fifty-second session. Executive Board. Comparison of methods of calculating equitable 
geographical distribution within the United Nations Common System (JIU/REP/96/7). Paris, 21 August 1997.

VATTEL, Emer de. O Direito das Gentes. [1758]. Brasília: Universidade de Brasília, 2004.

VIDAS, Davor; OSTRENG, Willy. Order for the Oceans at the Turn of the Century. The Hague: Kluwer Law International, 1999.

VIDIGAL, A.A.F.; CUNHA, Marcílio B.; FERNANDES, Luiz P. C.; MENDES, Izidério A.; SILVA, Nelio; OLIVEIRA, Lucimar L.; CUNHA JÚNIOR, Osmar B.; ALBUQUERQUE, Alexandre T. M.; RODRIGUEZ, Eliane G.; ALMEIDA, José A. N. Amazônia Azul: o mar que nos pertence. Rio de Janeiro: Ed. Record, 2006.

VISSCHER, Charles de. Les Avis Consultatifs de la Cour Permanente de Justice Internationale. RCADI, 1929-I, t. 26.

VITÓRIA, Francisco de. Os Índios e o Direito da Guerra (De Indis et de Jure Belli Relectiones - 1532). Ijuí, RS: Ed. da Unijuí, 2006.

WALKER, George K. Definitions for the Law of the Sea. Terms Not Defined by the 1982 Convention. Leiden, Boston: Martinus Nijhoff Publishers, 2012.

WELLING, Conrad G. Mining of the deep seabed in the year 2010. Lousiana Law Review, 1985, v. 45, n. 6.

WOLF, Ronald Charles. Effective international joint venture management. Practical legal insights for successful organization and implementation. London: M.E. Sharpe, 2000.

WOLFF, Christian. Jus Gentium Methodo Scientifica Pertractatum. [1764]. Oxford: Clarendon Press; London: Humphrey Milford, 1934, v. 2.

WOLFRUM, Rüdiger. The legal order for the seas and oceans. In: NORDQUIST, Myron H.; MOORE, John Norton (Eds.). Entry into force of the Law of the Sea Convention. The Hague: Martinus Nijhoff Publishers, 1995.

Germany and the Law of the Sea. In: TREVES, Túllio; PINESCHI, Laura. (Eds). The Law of the Sea. The European Union and its Member States. Boston/London/The Hague: Martinus Nijhoff Publishers, 1997.

Freedom of navigation: new challenges. International Tribunal for the Law of the Sea. In: NORDQUIST, M.H.; KOH, T.B.; MOORE, J. Norton (Orgs.). Freedom of seas, passage rights and the 1982 Law of the Sea Convention, 2009.

WORLD OCEAN REVIEW. Marine Resources. Opportunities and risks. Chapter 2: Seafloor Mining. Hamburg: Maribus GmbH, 2014.

YOUNG, Elizabeth; BALMASHANNAR, Ritchie-Calder of. Pacem in Maribus. Quiet enjoyment: arms control and police forces for the Ocean. Malta: The Royal University of Malta Press, 1971, v. I. 
ZHIXIONG, Wang. China and the exploitation of deep seabed polymetallic nodules. Marine Policy. March, 1991, v. 15, issue 2.

ZOU, Keyuan. China's Legal Reform: Towards the Rule of Law. Leiden/Boston: Martinus Nijhoff Publishers, 2006.

\section{Sites visitados}

BLUE MINING. Disponível em: 〈http://www.bluemining.eu/>. Acesso em: 13 mar. 2016.

CÂMARA DOS DEPUTADOS. Disponível em: 〈http://www2.camara.gov.br/>. Acesso em: 10 abr. 2014.

COMMISSION FOR THE CONSERVATION OF SOUTHERN BLUEFIN TUNA.

Disponível em: 〈https://www.ccsbt.org>. Acesso em: 10 jan. 2016.

COMMISSION SOUS-REGIONALE DES PECHES. Disponível em: <http://www.spcsrp.org/>. Acesso em: 12 jun. 2016.

COMPANHIA DE PESQUISA DE RECURSOS MINERAIS (CPRM). Disponível em: : <www.cprm.gov.br/>. Acesso em: 2 abr. 2016.

CORTE CENTROAMERICANA DE JUSTICIA. Disponível em: <http://www.portal.ccj.org.ni/>. Acesso em: 2 jan. 2015.

DE BEERS. Disponível em: http://www.debeersgroup.com. Acesso em 2 jan. 2017’.

DEUTSCHE WELLE. Disponível em: 〈http://www.dw.com>. Acesso em: 10 set. 2015.

EURONEWS. Disponível em: 〈http://www.euronews.com>. Acesso em: 10 set. 2015.

EUROPEAN COURT OF HUMAN RIGHTS. Disponível em: <https://www.echr.coe.int/>. Acesso em: 8 maio 2015.

EUROPEAN PARLIAMENT. Disponível em: 〈http://www.europarl.europa.eu/>. Acesso em: 6 fev. 2016.

EUROPEAN UNION LAW. Disponível em: 〈http://eur-lex.europa.eu >. Acesso em: 6 fev. 2016.

FACULDADE DE DIREITO DA UNIVERSIDADE DE SÃO PAULO. Disponível em: <https://www.direito.usp.br/>. Acesso em: 6 fev. 2016.

HIGH SEAS ALLIANCE. Disponível em: 〈http://highseasalliance.org/about-us >. Acesso em: 30 maio 2015.

INSTITUT OCÉANOGRAPHIQUE. Disponível em: <http://www.institut-ocean.org>. Acesso em: 7 set. 2016. 
INSTITUTO BRASILEIRO DE GEOGRAFIA E ESTATÍSTICA. Disponível em: <http://www.ibge.gov.br>. Acesso em: 4 out. 2015.

INTERNATIONAL CENTRE FOR SETTLEMENT OF INVESTMENT DISPUTES. Disponível em: <https://icsid.worldbank.org/>. Acesso em: 8 maio 2015.

INTERNATIONAL COMMITTEE OF THE RED CROSS. Disponível em: <http://www.icrc.org/>. Acesso em: 5 jun. 2015.

INTERNATIONAL COURT OF JUSTICE. Disponível em: <http://www.icj-cij.org/>. Acesso em: 22 maio 2016.

INTERNATIONAL SEABED AUTHORITY. Disponível em: <http://www.isa.org.jm>. Acesso em: 9 maio 2015.

INTERNATIONAL TRIBUNAL FOR THE LAW OF THE SEA. Disponível em: $<$ http://www.itlos.org/>. Acesso em: 9 maio 2015.

INTERNATIONAL WHALING COMMISSION (IWC). Disponível em: <http://iwc.int/home>. Acesso em: 22 maio 2014.

INTEROCEANMETAL JOINT ORGANIZATION. Disponível em: <http://www.iom.gov.pl/>. Acesso em: 6 mar. 2016.

MARINHA DO BRASIL. Disponível em: 〈http://www.marinha.mil.br $>$. Acesso em: 4 out. 2015.

MINISTÉRIO DE MINAS E ENERGIA. Disponível em: <http://mme.gov.br/>. Acesso em: 2 jan. 2017.

NATIONAL ENVIRONMENT AND PLANNING AGENCY. Government of Jamaica. Disponível em: 〈http://www.nepa.gov.jm>. Acesso em: 26 fev. 2016.

NATIONAL OCEANIC AND ATMOSPHERIC ADMINISTRATION. Disponível em: <http://www.gc.noaa.gov>. Acesso em: 17 fev. 2015.

NAUTILUS MINERALS INC. Disponível em: <http://www.nautilusminerals.com> Acesso em: 2 jan. 2017.

ORGANIZAÇÃO DAS NAÇÕES UNIDAS NO BRASIL. Disponível em: <http://www.onu.org.br>. Acesso em: 5 maio 2015.

PALÁCIO DO PLANALTO. Presidência da República. Disponível em: <http://www.planalto.gov.br/>. Acesso em: 8 maio 2015.

PERMANENT COURT OF ARBITRATION. Disponível em: 〈http://www.pca-cpa.org>. Acesso em: 23 mar. 2015.

PORT AUTHORITY OF JAMAICA. Disponível em: 〈http://www.portjam.com>. Acesso em: 26 fev. 2016. 
SOLWARAMINING. Disponível em: <http://www.solwaramining.org >. Acesso em: 2 jan. 2017.

THE GOVERNMENT OF THE REPUBLIC OF NAURU. Disponível em: <http://www.naurugov.nr>. Acesso em: 01 jan. 2016.

THE GUARDIAN. Disponível em: 〈https://www.theguardian.com/uk〉. Acesso em: 12 maio 2014.

THE KINGDOM OF TONGA. Disponível em: 〈http://ww.tongaportal.gov.to>. Acesso em: 01 jan. 2016.

THE LIBRARY OF CONGRESS. American Memory. Disponível em: <http://memory.loc.gov/>. Acesso em: 23 mar. 2015.

THE OCEAN FUNDATION. Disponível em: <https://www.oceanfdn.org>. Acesso em: 2 jan. 2017.

THE OFFICIAL WEBSITE OF THE BRITISH MONARCHY. Disponível em: <http://www.royal.gov.uk>. Acesso em: 7 abr. 2016.

UNITED KINGDOM LEGISLATION. Disponível em: 〈http://www.legislation.gov.uk> Acesso em: 7 abr. 2016.

UNITED NATIONS DEVELOPING PROGRAMME. Disponível em: <http://www.undp.org >. Acesso em: 27 fev. 2016.

UNITED NATIONS EDUCATIONAL, SCIENTIFIC AND CULTURAL ORGANIZATION (UNESCO). Disponível em: 〈http://whc.unesco.org/>. Acesso em: 12 fev. 2015.

UNITED NATIONS ENVIRONMENT PROGRAMME. Disponível em: <http://www.unep.org >. Acesso em: 10 abr. 2015.

UNITED NATIONS. Disponível em: 〈http://www.un.org>. Acesso em: 10 abr. 2015.

WALTHER-SCHUECKING-INSTITUT. Disponível em: <https://www.wsi.unikiel.de/en>. Acesso em: 12 fev. 2015.

WORLD BANK. Disponível em: 〈http://www.worldbank.org/>. Acesso em: 8 maio 2015.

WORLD TRADE ORGANIZATION. Disponível em: <https://www.wto.org >. Acesso em: 18 fev. 2016. 


\section{ANEXO - IMAGENS}

\section{IMAGEM 1 \\ CONTRATOS DE EXPLORAÇÃO EMITIDOS PELA AUTORIDADE DOS FUNDOS MARINHOS INTERNACIONAIS}

Extensão total da Área (laranja); mar sob jurisdição estatal (azul); pleitos de extensão da plataforma continental dos países costeiros junto à Comissão de Limites da Plataforma Continental (vermelho); contratos de exploração de nódulos polimetálicos (verde); contratos de exploração de sulfetos polimetálicos (roxo); contratos de exploração das crostas ricas em cobalto (azul), expedidos pela Autoridade dos Fundos Marinhos Internacionais.

\section{Exploration contracts issued by ISA}

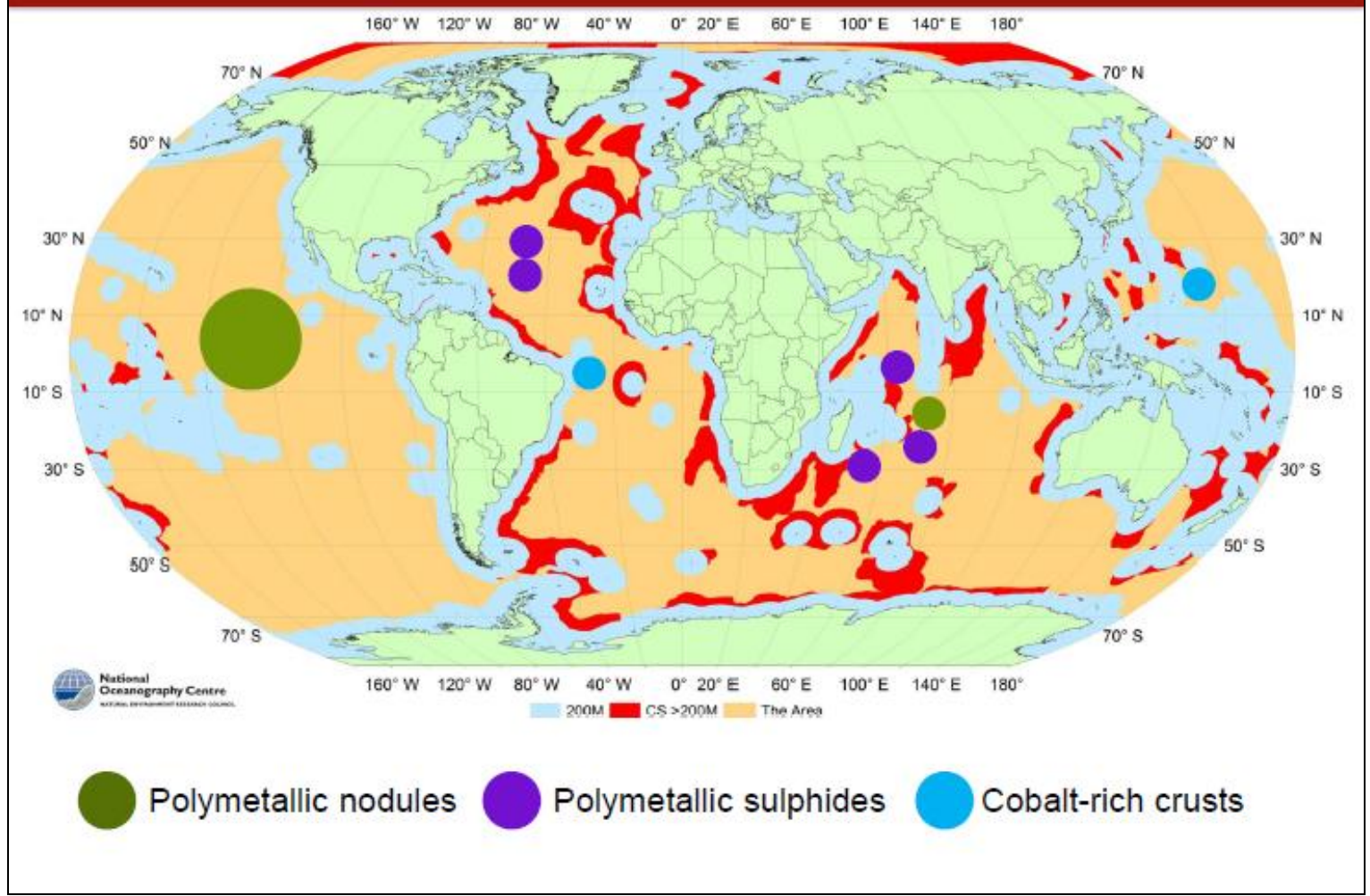

Fonte: LODGE, Michael W. Deep seabed mining: the regulatory regime. Seminar. International Seabed Authority Kingston, Jamaica, 17 March 2015. Disponível em: https://www.isa.org.jm/files/documents/EN/ Seminars/2015/Lodge-2.pdf. Acesso em: 01 fev. 2016. 


\section{IMAGEM 2}

\section{EXTENSÃO DA ÁREA, REGIÃO MARÍTIMA SOB JURISDIÇÃO DA AUTORIDADE DOS FUNDOS MARINHOS INTERNACIONAIS}

Ordem das cores: Estados que apresentaram propostas ao CLPC; Estados que apresentaram informações preliminares mas não divulgaram a extensão da área; Zona Econômica Exclusiva; Área da plataforma continental exterior, de acordo com os Sumários Executivos propostos; Área da plataforma continental exterior, de acordo com informações preliminares.

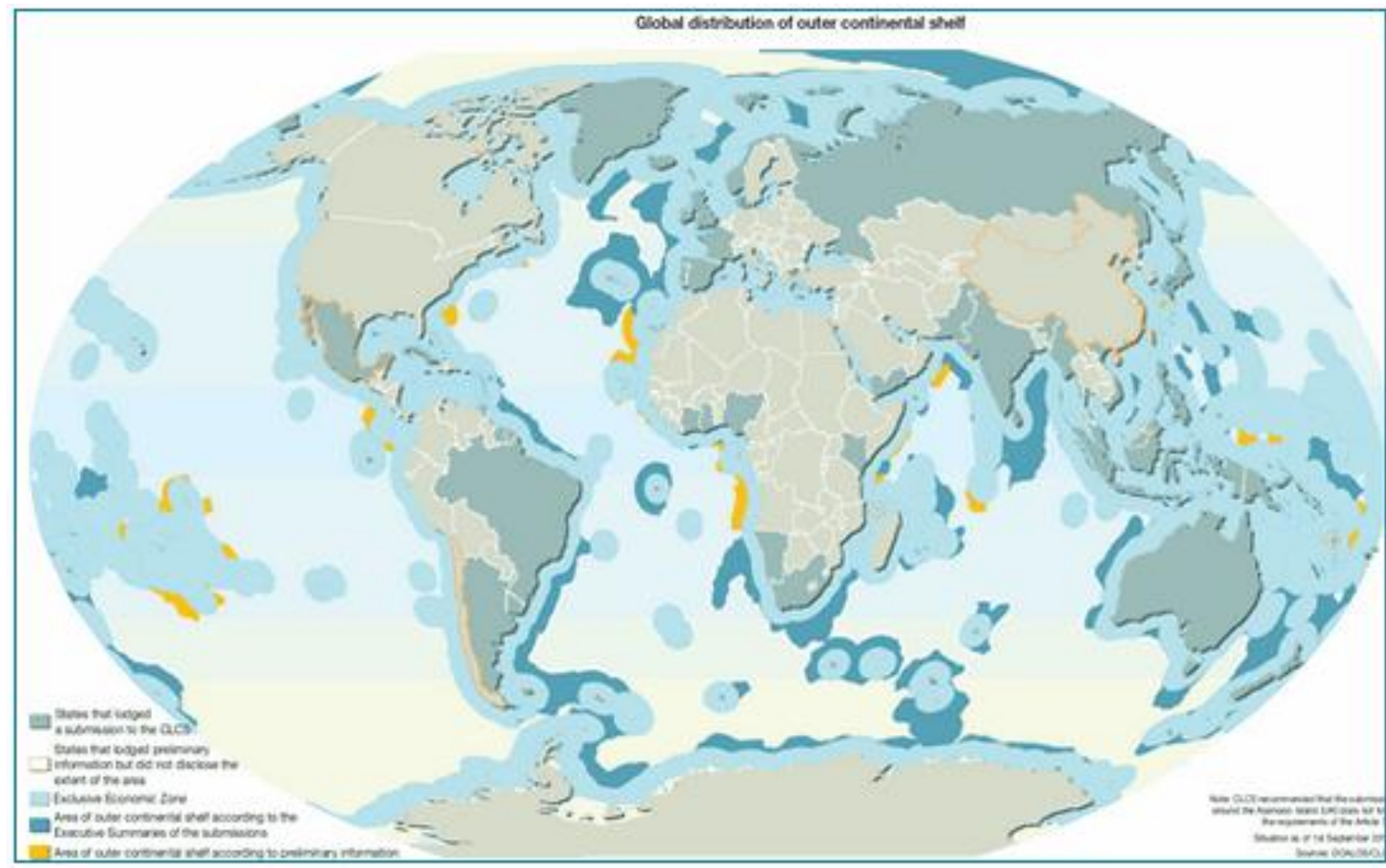

Fonte: DOALOS - CLCS. CONTINENTAL SHELF. The Last Maritime Zone. UNEP. Published by UNEP-GRID-Arendal. 2009. ISBN 978-82-7701-059-5. Printed by Birkeland Trykkeri AS. Norway. Disponível em: http://www.grida.no/publications/shelf-last-zone/page.aspx?id=4691. Acesso em: 8 set. 2016. 


\section{IMAGEM 3 \\ REPRESENTAÇÃO GRÁFICA DA EXTENSÃO DA ÁREA}

Ordem das cores: a Jurisdição dos Fundos Marinhos; totais estimados; área sob jurisdição estatal (até 200 milhas marítimas desde a linha de base); fundos marinhos além das 200 milhas marítimas; Área (fronteiras finais a serem determinadas, seguindo o traçado da plataforma continental exterior); Área da plataforma continental exterior pleiteada pelos países; Área para as quais as recomendações já tenham sido realizadas e o sumário já foi publicado; Área estimada da plataforma continental exterior indicada nas informações preliminares submetidas pelos Estados. Cada quadrado equivale a 1 milhão de quilômetros quadrados.

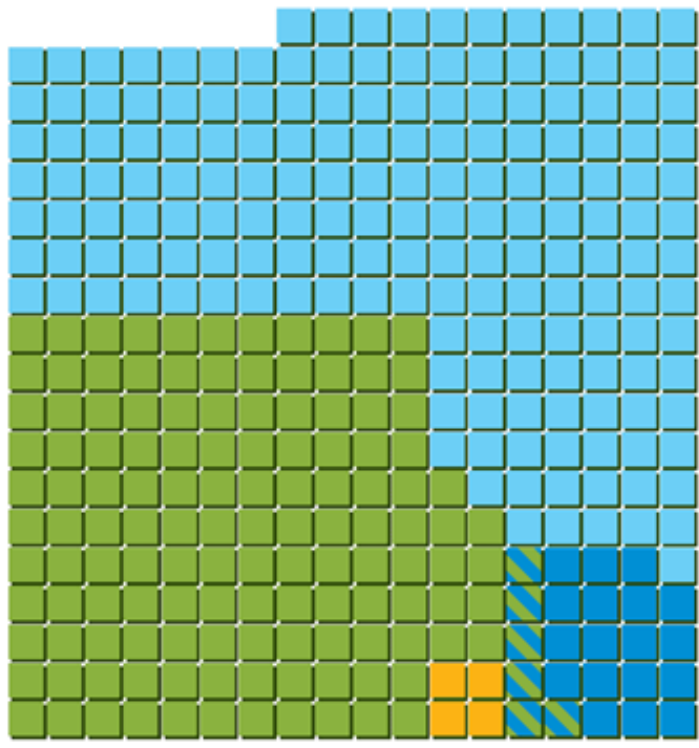

Seabed Jurisdiction. Estimated totals

(up to $200 \mathrm{M}$ from the baseline) Seabed area beyond $200 \mathrm{M}$ :

The Area (final boundary to be determined following

the delineation of the outer continental shelf)

Area of outer continental shelf submitted by States ${ }^{\circ}$

Area for which recommendations have been made and

a summary has been made public

Estimated area of outer continental shelf indicated in preliminary information submitted by States

\rfloor$=1$ million square kilometres

Sources: DOALOS/CLCS; Global Maritime Boundaries Database, 2010

Fonte: DOALOS - CLCS. CONTINENTAL SHELF. The Last Maritime Zone. UNEP. Published by UNEP-GRID-Arendal. 2009. ISBN 978-82-7701-059-5. Printed by Birkeland Trykkeri AS. Norway.

Disponivel em: hhtp://www.grida.no publications/shelf-lastzone page. aspx?id=4691 - Acesso em 26 de Julho de 2016

Fonte: DOALOS - CLCS. CONTINENTAL SHELF. The Last Maritime Zone. UNEP. Published by UNEPGRID-Arendal. 2009. ISBN 978-82-7701-059-5. Printed by Birkeland Trykkeri AS. Norway. Disponível em: http://www.grida.no/publications/shelf-last-zone/page.aspx?id=4691. Acesso em: 8 set. 2016. 


\section{IMAGEM 4}

\section{ESPAÇOS MARÍTIMOS DISCIPLINADOS PELA CONVENÇÃO DAS NAÇÕES UNIDAS SOBRE O DIREITO DO MAR DE 1982}

Dimensões Horizontal (mar territorial, zona contígua, zona econômica exclusiva e o alto mar) e Vertical (plataforma continental, plataforma continental exterior e Área).

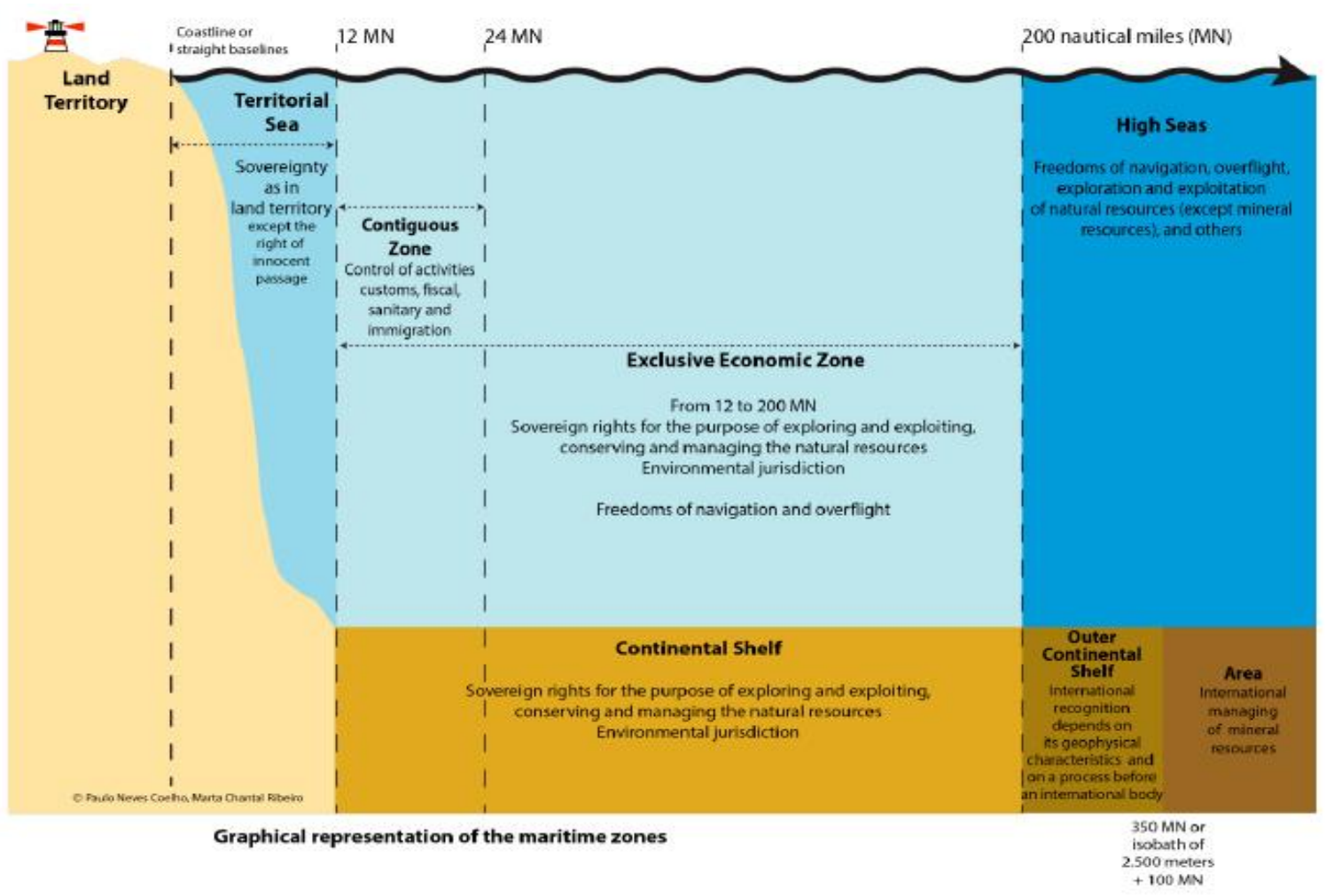

Território terrestre, costa ou linhas de base; mar territorial, até 12 milhas marítimas (soberania como no território terrestre, exceto quanto ao direito de passagem inocente); Zona Contígua, entre 12 e 24 milhas marítimas (controle de atividades aduaneiras, fiscais, sanitárias e de imigração); Zona Econômica Exclusiva, de 24 a 200 milhas marítimas (direitos soberanos para o propósito de exploração e explotação, conservação e gestão dos recursos naturais. Jurisdição ambiental. Liberdade de navegação e de sobrevoo); Alto Mar, a partir das 200 milhas marítimas (liberdade de navegação, sobrevoo, exploração e explotação dos recursos naturais (exceto recursos minerais) e outros); Plataforma Continental, de 12 a 200 milhas marítimas (direitos soberanos para exploração e explotação, conservação e gestão dos recursos naturais, jurisdição ambiental); Plataforma Continental Exterior, de 200 a 350 milhas marítimas ou isóbata de 2.500 metros (reconhecimento internacional depende de suas características geofísicas e de um processo perante um órgão internacional); Área (gestão internacional dos recursos minerais).

Fonte: RIBEIRO, Martha Chantal. Institut Oceanographic. Disponível em: http://www.institut-ocean.org/ rubriques.php?lang=fr\&article $=1367503042 \&$ categ=265713871\&sscategorie=1324551762. Acesso em: 7 set. 2016. 


\section{IMAGEM 5}

\section{ZONA DE FRATURA CLARION-CLIPPERTON}

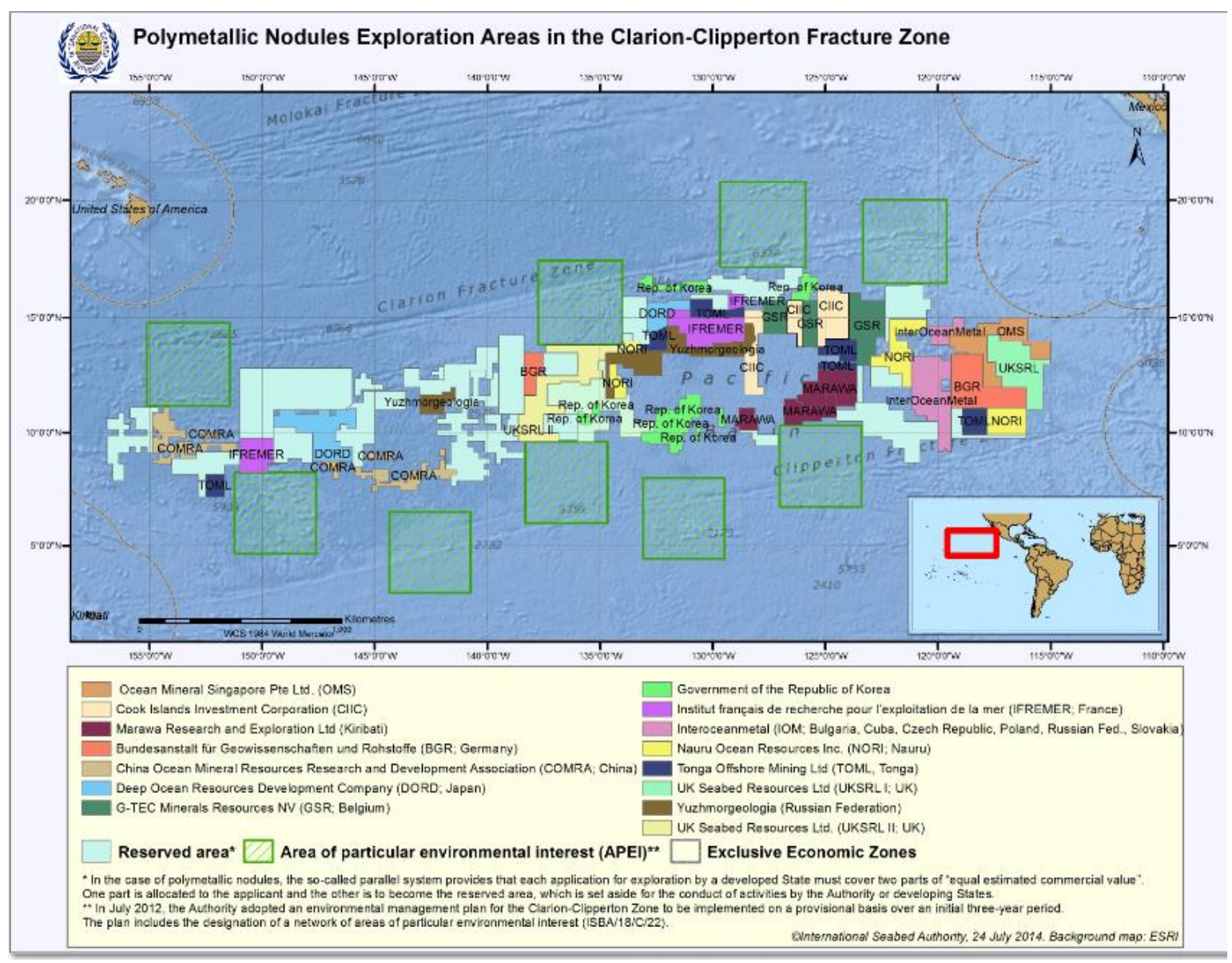

“Áreas de Exploração de Nódulos Polimetálicos na Zona de Fratura ClarionClipperton". São identificadas, no mapa e na respectiva lista, as áreas cuja autorização para exploração foi concedida pela Autoridade dos Fundos Marinhos Internacionais às respectivas entidades identificadas. $\mathrm{Na}$ sequência de cores da tabela encontra-se identificada, em azul claro, a "Área Reservada", com o respectivo esclarecimento: "No caso dos nódulos polimetálicos, o chamado 'sistema paralelo' determina que cada pedido de exploração realizado por um Estado desenvolvido deve cobrir duas partes de 'igual valor comercial estimado'. Uma parte é alocada ao requerente e a outra deverá tornar-se uma área reservada, a qual é separada para que sejam conduzidas atividades pela Autoridade ou por Estados em desenvolvimento". Em verde listrado encontra-se a "área de interesse ambiental particular (APEI)", com a seguinte explanação: "Em julho de 2012, a Autoridade adotou um plano de gestão ambiental para a Zona de Fratura ClarionClipperton a ser implementado de forma provisória pelo período inicial de três anos. $\mathrm{O}$ plano inclui a designação de uma rede de áreas de interesse ambiental particular (ISBA/18/C/22)".

Fonte: AUTORIDADE DOS FUNDOS MARINHOS INTERNACIONAIS. Disponível em: https://www.isa. org.jm/contractors/exploration-area . Acesso em: 8 set. 2016. 


\section{IMAGEM 6}

\section{CORDILHEIRA MESOATLÂNTICA}

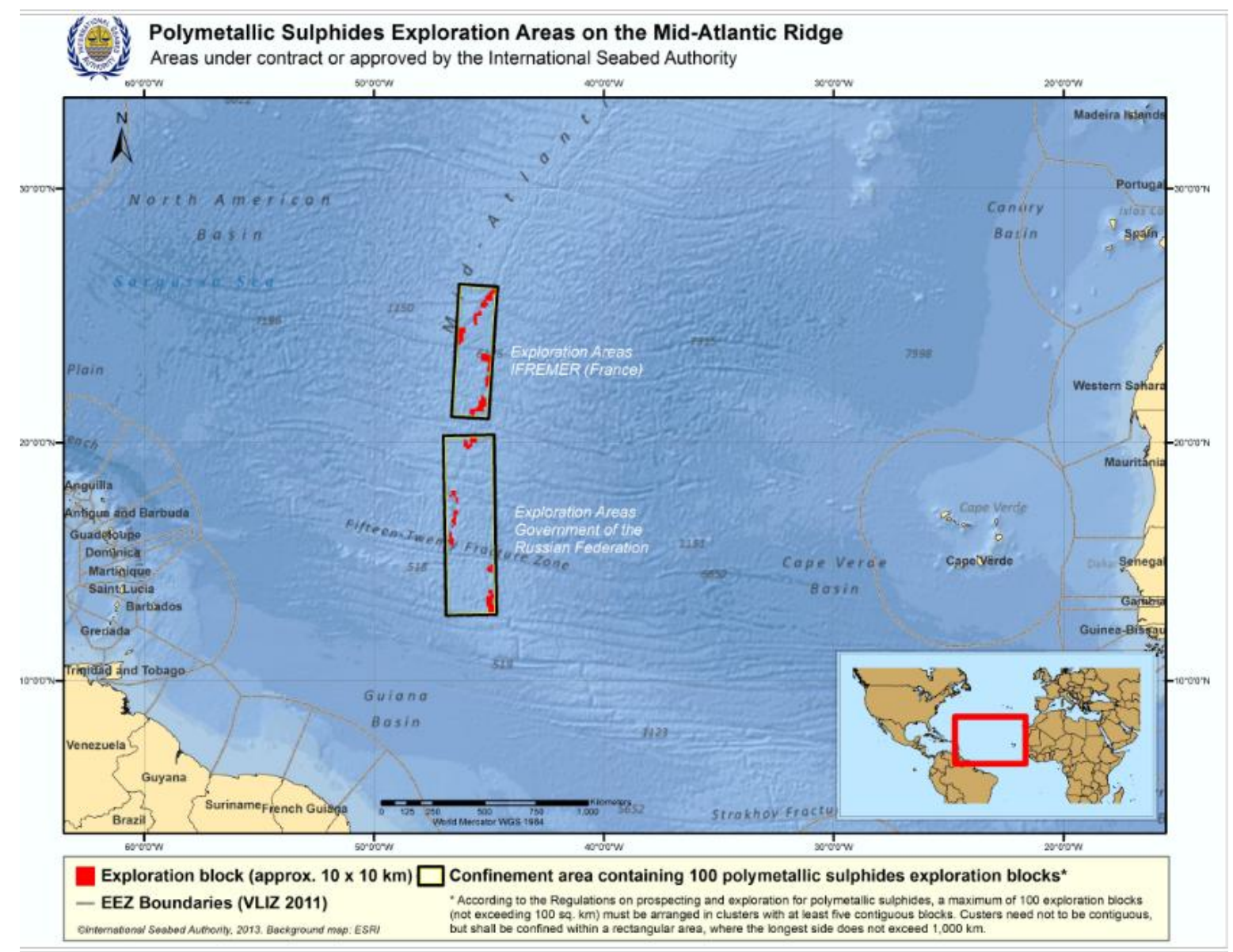

“Áreas de Exploração de Sulfetos Polimetálicos na Cordilheira Mesoatlântica”. Em vermelho encontram-se os "blocos de exploração", cujo tamanho individual aproximado é de $10 \mathrm{~km}^{2}$, sendo que enquanto a exploração dos blocos do campo superior foi concedida pela Autoridade à francesa IFREMER, os blocos do campo inferior foram concedidos pela Autoridade para exploração pelo Governo da Rússia. A "área de confinamento contendo 100 blocos para exploração dos sulfetos polimetálicos", também identificada no mapa, tem o seguinte esclarecimento: "De acordo com os Regulamentos sobre a prospecção e exploração dos sulfetos polimetálicos, o máximo de 100 blocos para exploração (que não excedam $100 \mathrm{~km}^{2}$ ) deve ser disposto em grupos com, no mínimo, cinco blocos contíguos. Os grupos não precisam ser contíguos, mas devem ser dispostos dentro de uma área retangular, onde o lado mais comprido não deve exceder $1.000 \mathrm{~km}$ ”.

Fonte: AUTORIDADE DOS FUNDOS MARINHOS INTERNACIONAIS. Disponível em: https://www.isa. org.jm/contractors/exploration-area. Acesso em: 8 set. 2016. 


\section{IMAGEM 7}

\section{ÁREAS DE EXPLORAÇÃO DE NÓDULOS POLIMETÁLICOS E SULFETOS POLIMETÁLICOS LOCALIZADOS NOS FUNDOS MARINHOS INTERNACIONAIS SOB O OCEANO ÍNDICO}

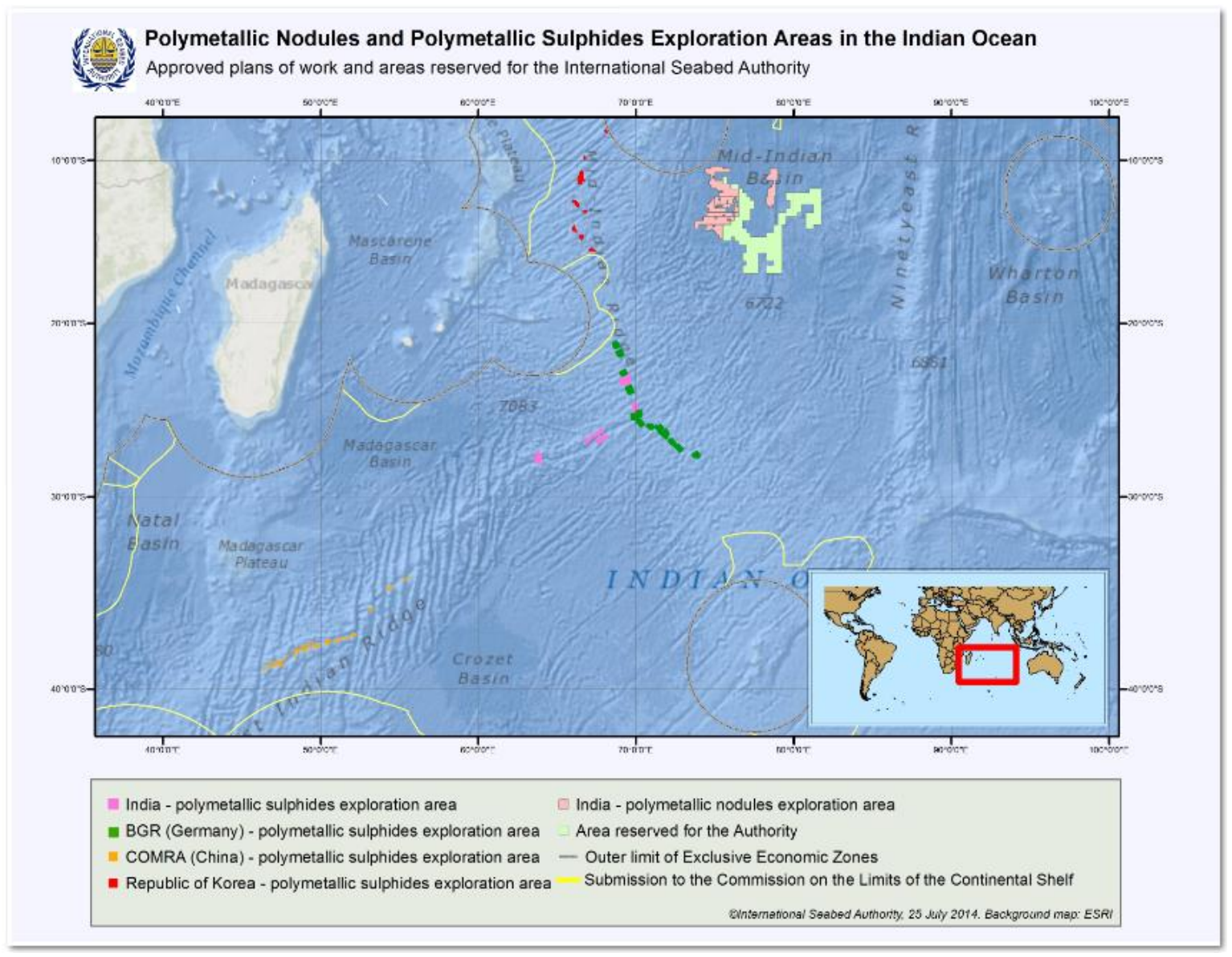

"Áreas de Exploração de Nódulos Polimetálicos e Sulfetos Polimetálicos Localizados nos Fundos Marinhos Internacionais sob o Oceano Índico". No mapa, e na lista de cores seguinte, encontram-se as entidades para as quais a Autoridade dos Fundos Marinhos Internacionais concedeu a autorização para exploração dos nódulos polimetálicos e sulfetos polimetálicos, localizados nos fundos marinhos internacionais, situados no Oceano Î́ndico. São identificadas, também, as "áreas reservadas" (azul claro), bem como os limites das Zonas Econômicas Exclusivas dos respectivos Estados costeiros (linhas cinzas) e os pedidos realizados pelos países para reconhecimento de sua plataforma continental exterior junto à Comissão dos Limites da Plataforma Continental.

Fonte: AUTORIDADE DOS FUNDOS MARINHOS INTERNACIONAIS. Disponível em: https://www.isa. org.jm/contractors/exploration-area. Acesso em: 8 set. 2016. 


\section{IMAGEM 8}

\section{ÁREAS DE EXPLORAÇÃO DE CROSTAS DE FERROMANGANÊS RICAS EM COBALTO NO OCEANO PACÍFICO}

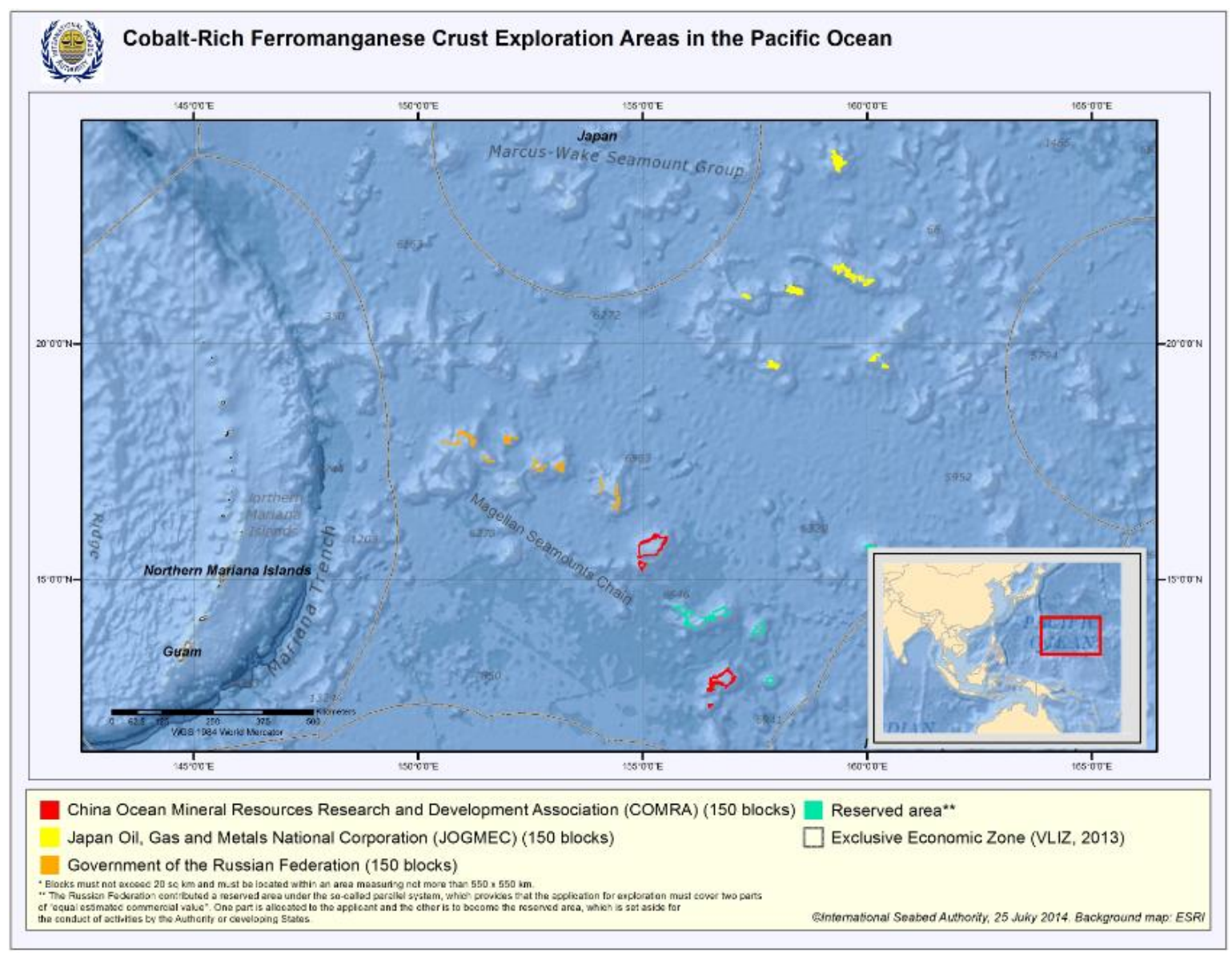

“Áreas de Exploração de Crostas de Ferromanganês Ricas em Cobalto no Oceano Pacífico". Identificam-se no mapa, e na respectiva lista, as entidades para as quais foram concedidas as autorizações, pela Autoridade, para exploração das crostas de ferromanganês ricas em cobalto no Oceano Pacífico. Consta, ainda, a "Área reservada", em azul claro, com a seguinte informação: "A Federação Russa contribuiu com uma área reservada de acordo com o chamado 'sistema paralelo', o qual estabelece que o requerimento para exploração deve cobrir duas partes de 'igual valor comercial estimado'. Uma parte é alocada ao requerente e a outra parte deve tornar-se uma área reservada, a qual deve ser separada para que sejam conduzidas atividades pela Autoridade ou por Estados em desenvolvimento".

Fonte: AUTORIDADE DOS FUNDOS MARINHOS INTERNACIONAIS. Disponível em: https://www.isa. org.jm/contractors/exploration-area. Acesso em: 8 set. 2016. 


\section{IMAGEM 9}

\section{RECURSOS MINERAIS LOCALIZADOS NOS FUNDOS MARINHOS INTERNACIONAIS SOB O OCEANO PACÍFICO SUL}

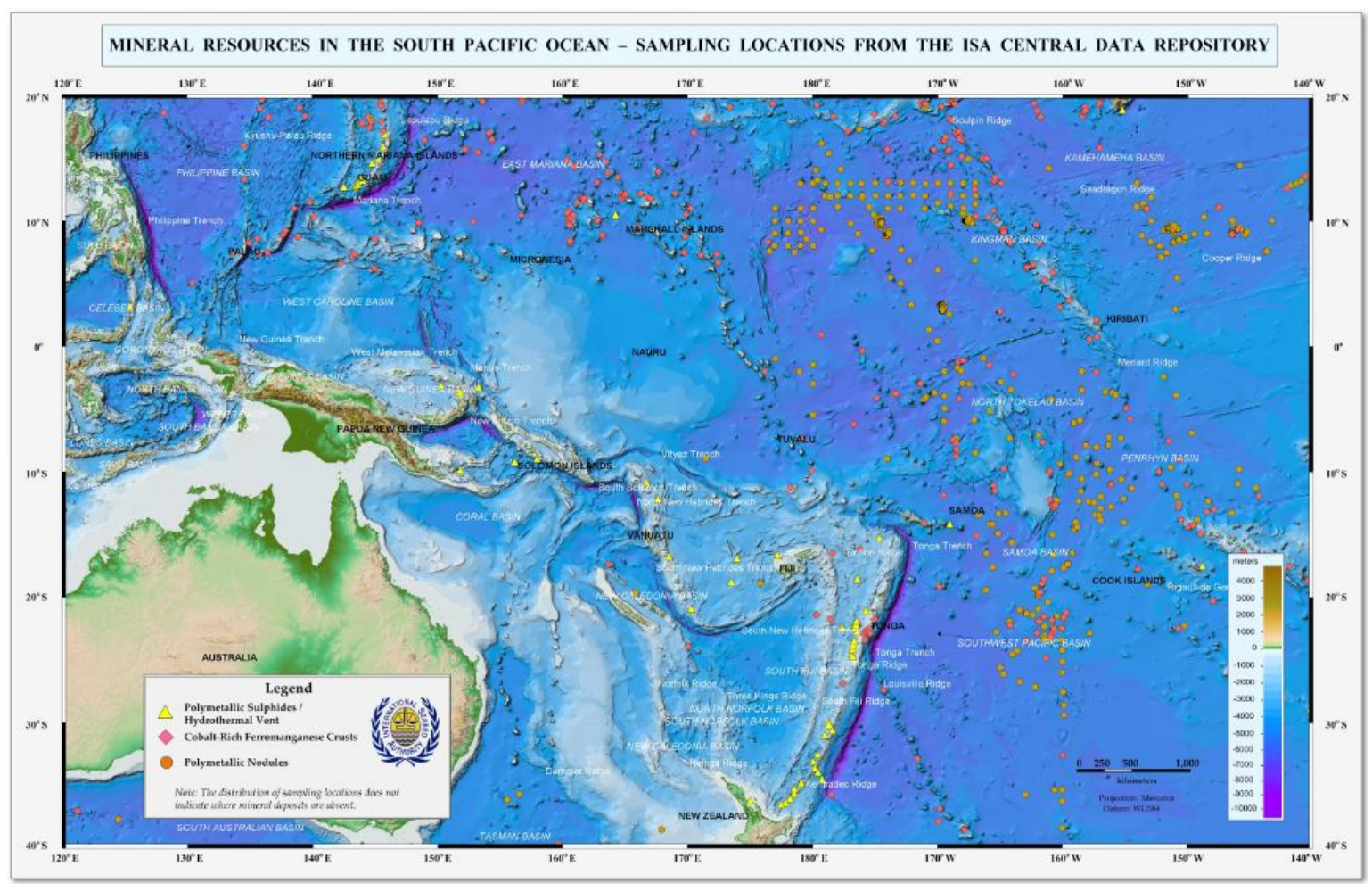

"Recursos Minerais localizados nos Fundos Marinhos Internacionais no Oceano Pacífico Sul". Este mapa identifica os recursos minerais situados nos fundos marinhos internacionais situados sob o Oceano Pacífico Sul. Os triângulos amarelos identificam os sulfetos polimetálicos e fontes hidrotermais, sendo que os losangos rosas identificam as crostas de ferromanganês ricas em cobalto, enquanto os círculos laranjas representam os nódulos polimetálicos.

Fonte: AUTORIDADE DOS FUNDOS MARINHOS INTERNACIONAIS. Disponível em: https://www.isa. org.jm/contractors/exploration-area. Acesso em: 8 set. 2016. 


\section{IMAGEM 10}

\section{MONTANHAS MARINHAS DO ATLÂNTICO SUL}

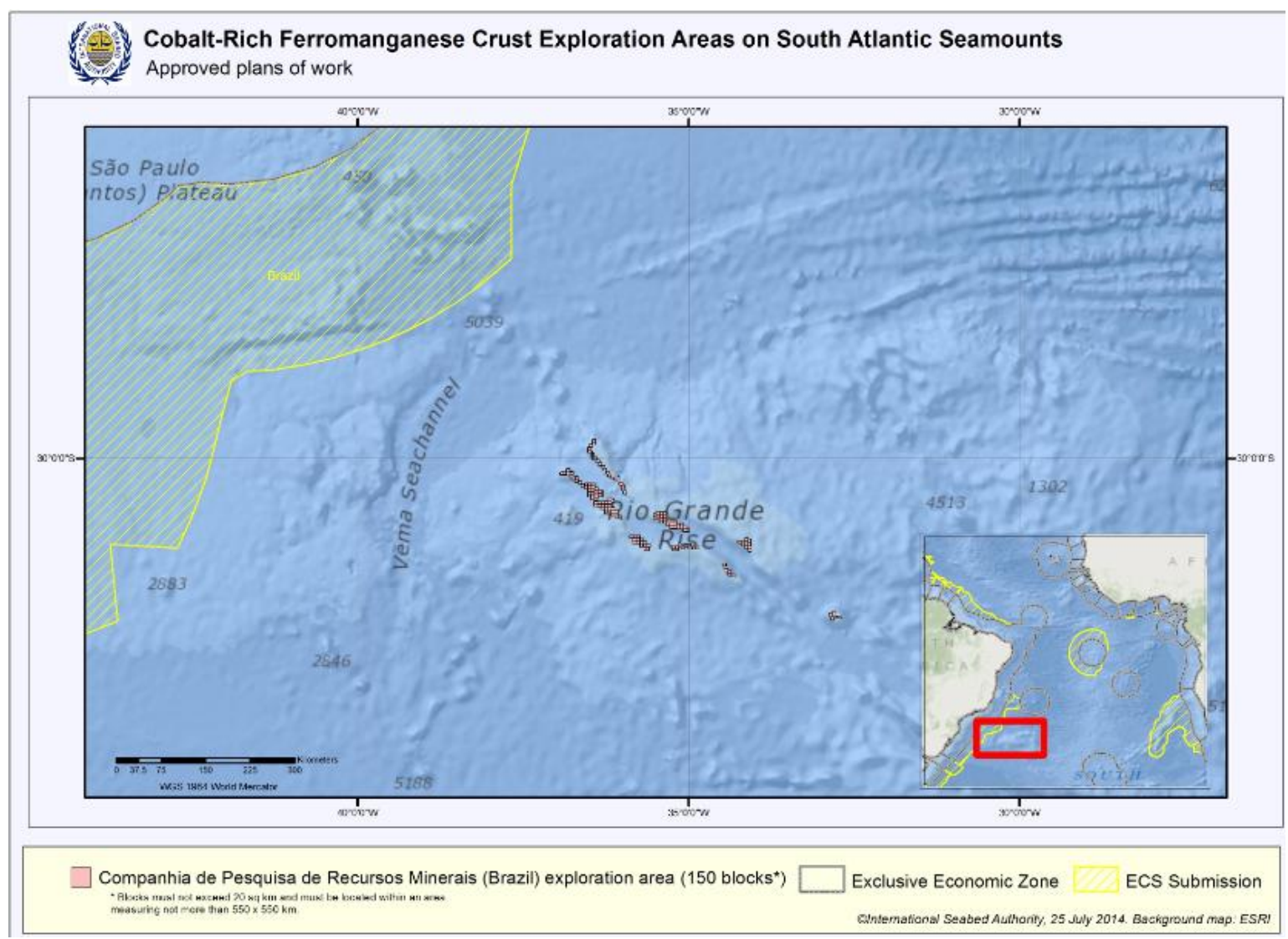

"Áreas de Exploração de Crostas de Ferromanganês ricas em Cobalto nas Montanhas Marinhas do Atlântico Sul". O mapa mostra as áreas concedidas pela Autoridade dos Fundos Marinhos Internacionais para exploração pela Companhia de Pesquisa de Recursos Minerais, sendo que os blocos de exploração não podem exceder 20 $\mathrm{km}^{2}$ e devem ser alocados dentro uma área que não meça mais de $550 \mathrm{~km}^{2}$. Identificam-se, ainda, a Zona Econômica Exclusiva e, em amarelo, os pedidos de reconhecimento das plataformas continentais exteriores junto à Comissão dos Limites da Plataforma Continental.

Fonte: AUTORIDADE DOS FUNDOS MARINHOS INTERNACIONAIS. Disponível em: https://www.isa. org.jm/contractors/exploration-area. Acesso em: 8 set. 2016. 


\section{IMAGEM 11}

\section{LOCALIZAÇÃO DE NÓDULOS POLIMETÁLICOS E DEPÓSITOS DE CROSTAS}

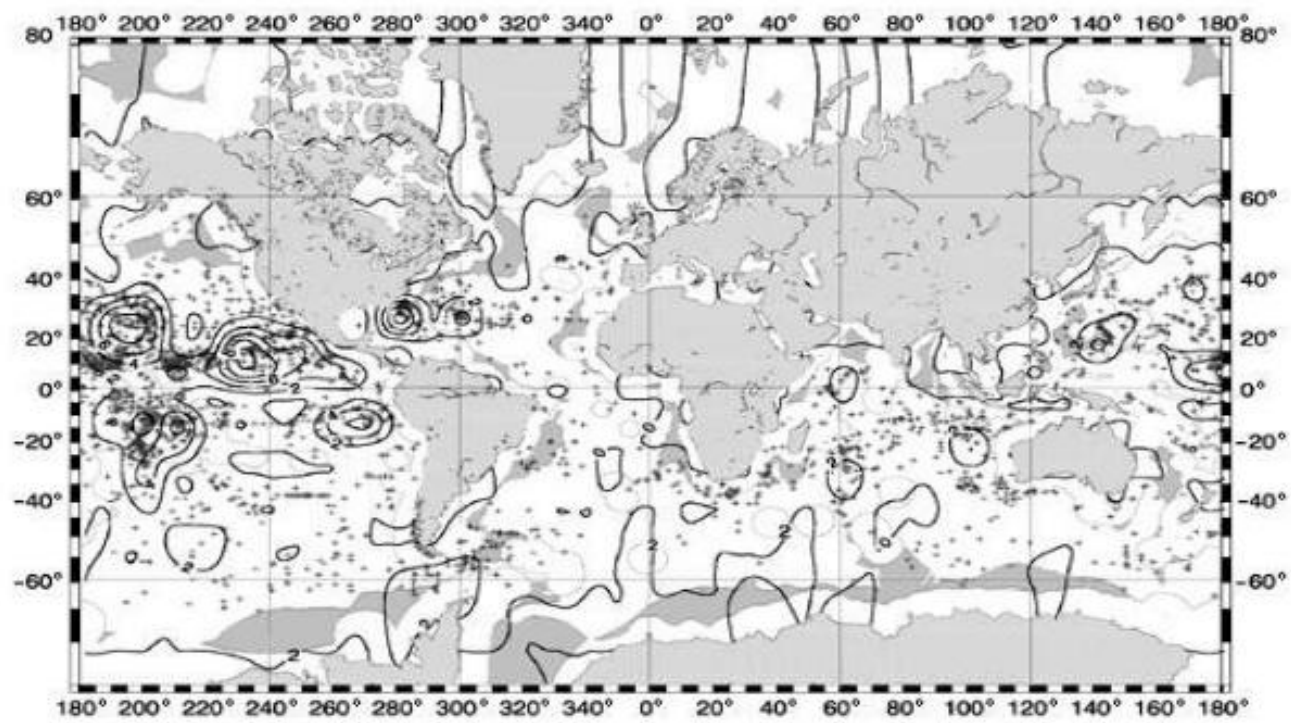

Figure 3 - Location of all reported marine manganese nodule and crust deposits (in crosses - after: NOAA \& MMS Marine Minerals CD-ROM Data Set, World Data Center for Marine Geology \& Geophysics. Boulder, 1991: Gross \& Mcleod, 1987: Kesler, 1994, and other sources cited in the text) with reference to the ELCS regions (in grey) and EEZ areas (outlined by thin curved grey lines). Contours (black lines) are abundance of noxlules and crusts on the seafloor in $\mathrm{kg} / \mathrm{m}^{2}$ and gridded on a $\mathrm{I}^{-}$latitude and longitude basis from data compiled from the sources cited.

"Localização de todos os nódulos marinhos de manganês e depósitos de crostas reportados. NOAA (National Oceanic and Atmospheric Administration - U.S. Department of Commerce) e MMS Marine Minerais. Worls Data Center for Marine Geology \& Geophysics (Boulder, 1991; Gross \& McLeod, 1987; Kesler, 1994 et al.).

Fonte: MURTON, Bramley J. A Global Review of Non-Living Resources on the Extended Continental Shelf. Southampton Oceanography Centre. UK. Disponível em: http://www.scielo.br/scielo.php?script=sci_arttext\&pid=S0102-261X2000000300007. Acesso em: 2 jan. 2017. 


\section{IMAGEM 12}

\section{NÓDULOS POLIMETÁLICOS}

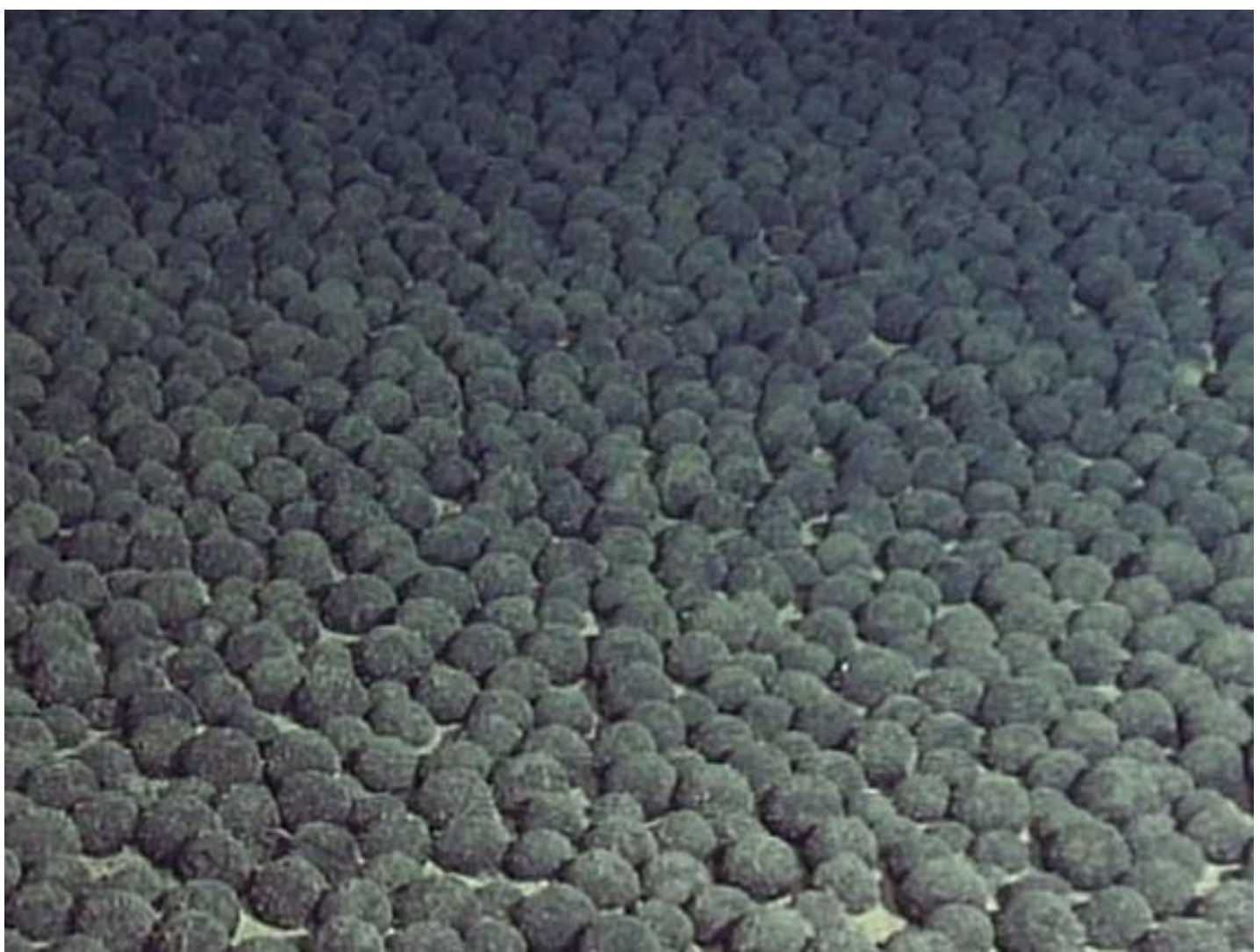

Fonte: THE ECONOMIC TIMES. Disponível em: http://economictimes.indiatimes.com Inews/economy/policy/government-to-extend-pact-with-isa-on-exploring-manganese-nodules/ articleshow/54291313.cms. Acesso em: 2 jan. 2017.

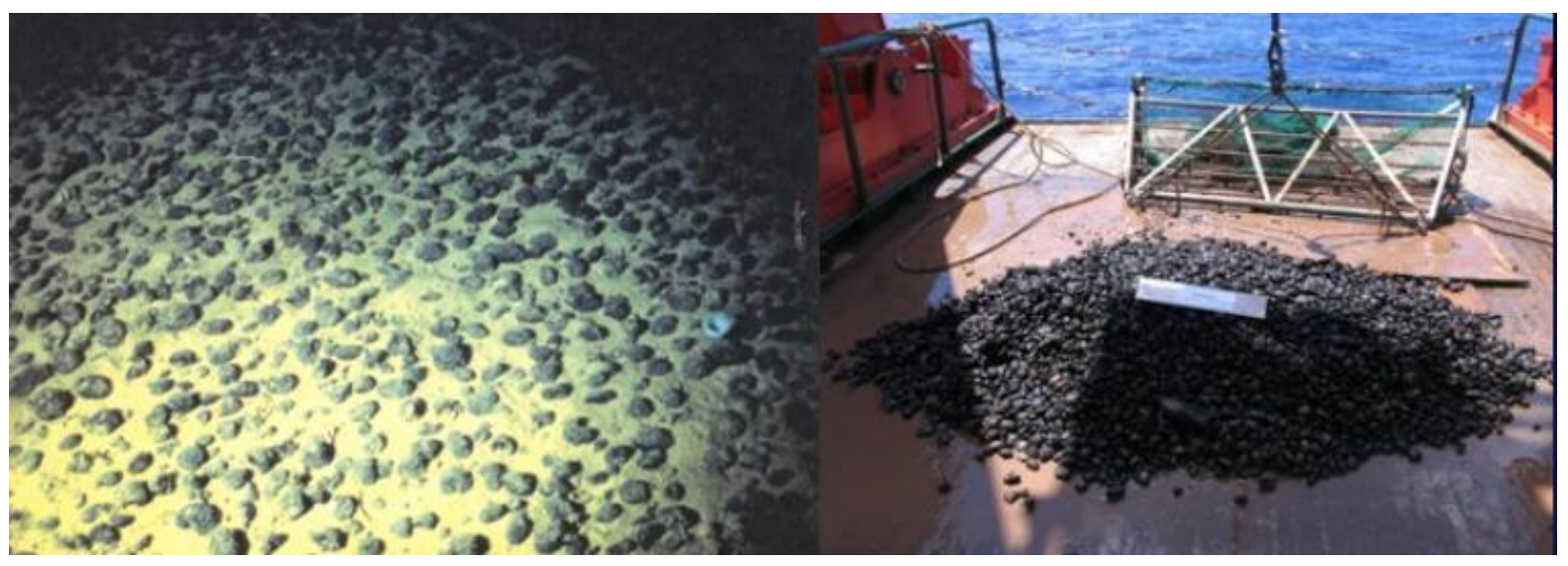

Fonte: SECRETARIA DE CIÊNCIA, TECNOLOGIA E INOVAÇÃO DA MARINHA. II Simpósio de Ciência, Tecnologia e Inovação. A Importância Presente e Futura do Mar. Rio de Janeiro, 21 a 23 de Setembro de 2011. Disponível em: http://slideplayer.com.br/slide/1869552/ - Acesso em: 2 jan. 2017 


\section{IMAGEM 13}

\section{NÓDULOS POLIMETÁLICOS}

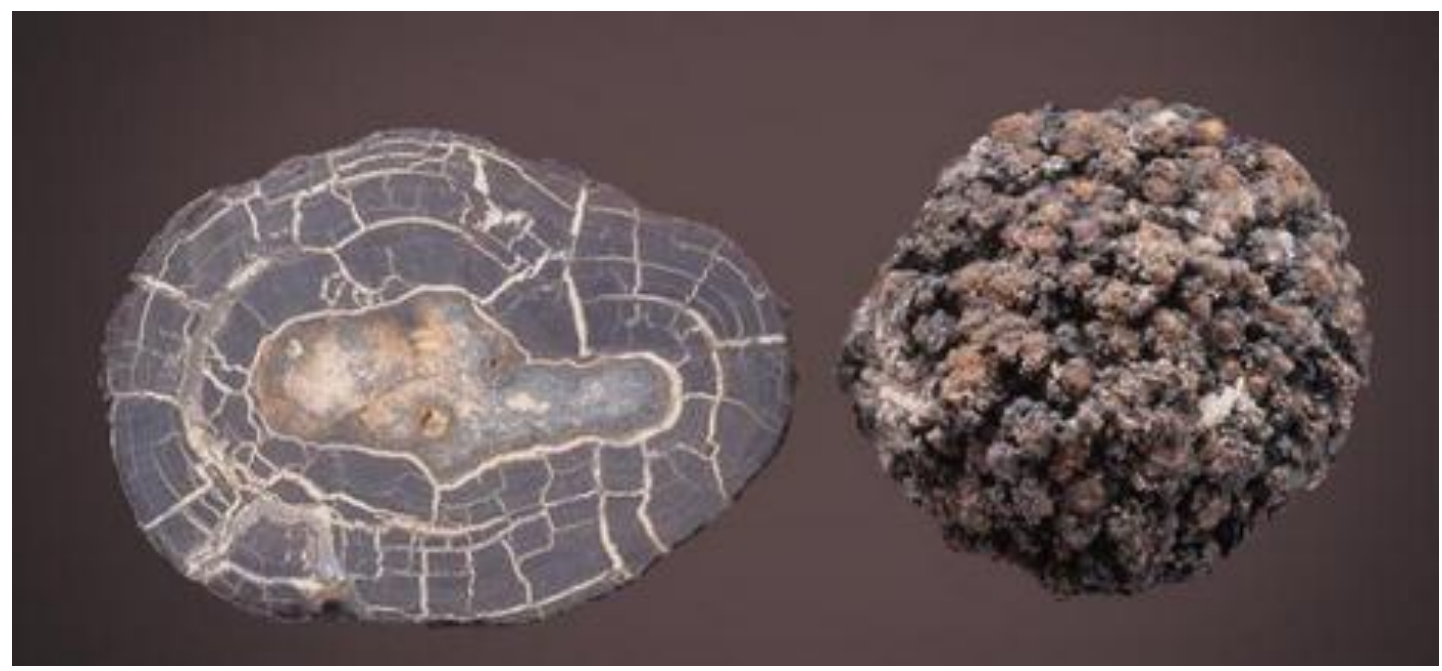

Fonte: AUTORIDADE DOS FUNDOS MARINHOS INTERNACIONAIS. Disponível em: https://www.isa.org.jm/ - Acesso em: 2 jan. 2017.

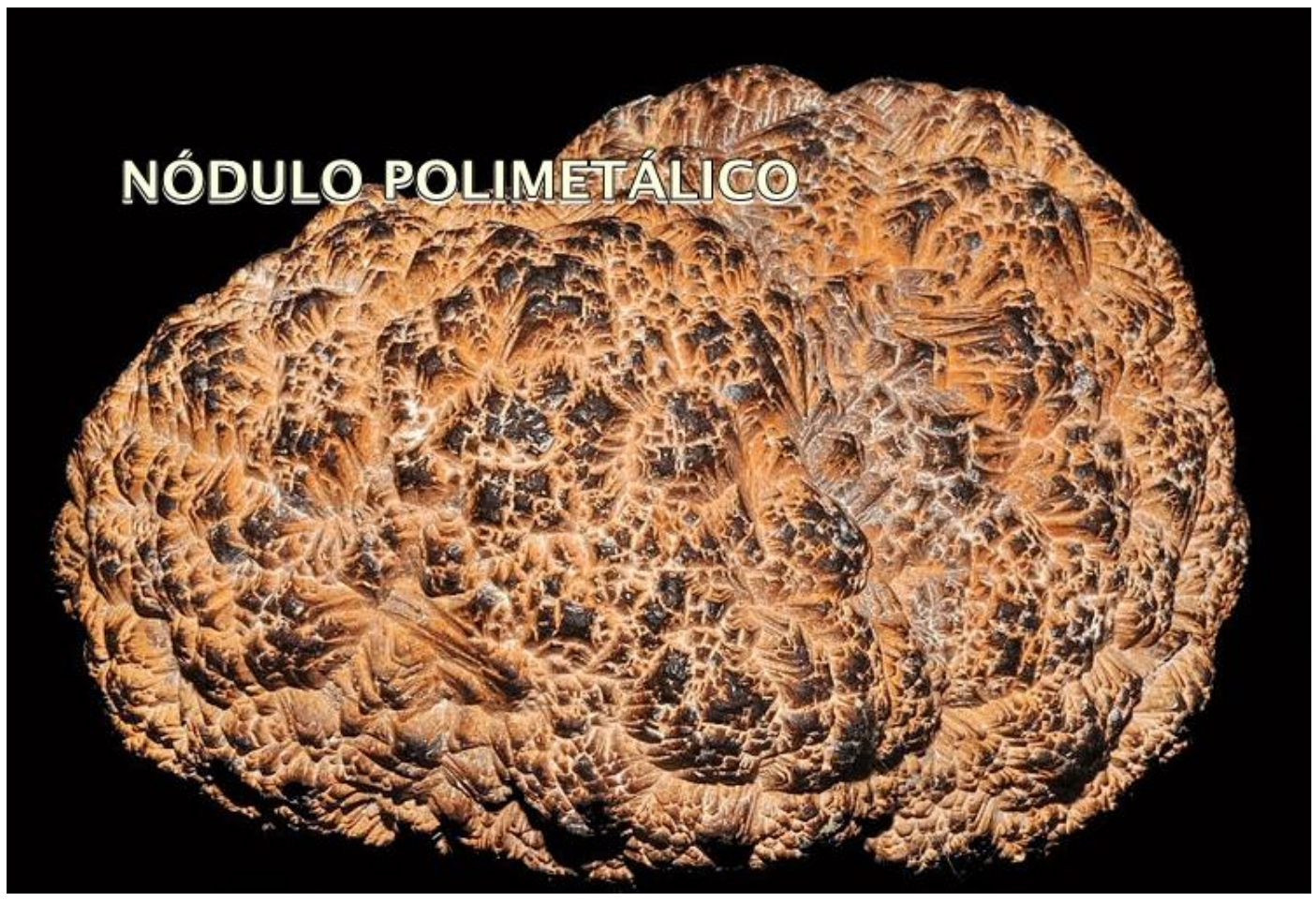

Fonte: DIARIO DE CANARIAS. Disponível em: http://diariodecanarias.net/wpcontent/uploads/2013/06/1112inodulopolimetalico.jpg - Acesso em: 2 jan. 2017. 